Supporting Information

\title{
Proline Ester Enolate Claisen Rearrangement and Formal Total Synthesis of (-)-Cephalotaxine
}

\author{
Hongjun Jeon, Yundong Chung and Sanghee Kim* \\ College of Pharmacy, Seoul National University, 1 Gwanak-ro, Gwanak-gu, Seoul 08826, Republic of Korea
}

pennkim@snu.ac.kr

Table of Contents
A. ${ }^{1} \mathrm{H}$ and ${ }^{13} \mathrm{C}$ NMR Data Comparison for Intermediate I
B. Chiral HPLC Chromatograms of Compound 20
S3
C. Copies of Spectra $\left({ }^{1} \mathrm{H}\right.$ NMR, ${ }^{13} \mathrm{C}$ NMR)
$\mathrm{S} 4-\mathrm{S} 23$ 


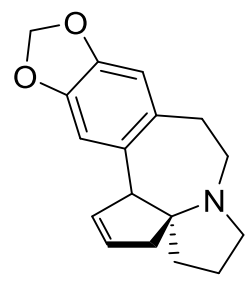

intermediate I

\begin{tabular}{|c|c|c|c|}
\hline \multicolumn{2}{|c|}{${ }^{1} \mathbf{H}$ NMR } & \multicolumn{2}{|c|}{${ }^{13} \mathrm{C}$ NMR } \\
\hline Mori $^{a}$ & This work ${ }^{b}$ & Mori $^{c}$ & This work ${ }^{d}$ \\
\hline $6.65(\mathrm{~s}, 1 \mathrm{H})$ & $6.64(\mathrm{~s}, 1 \mathrm{H})$ & 146.2 & 146.2 \\
\hline $6.59(\mathrm{~s}, 1 \mathrm{H})$ & $6.58(\mathrm{~s}, 1 \mathrm{H})$ & 145.9 & 145.8 \\
\hline $5.89(\mathrm{~d}, J=1.5 \mathrm{~Hz}, 1 \mathrm{H})$ & $5.88(\mathrm{~d}, J=1.7 \mathrm{~Hz}, 1 \mathrm{H})$ & 132.3 & 132.24 \\
\hline $5.88(\mathrm{~d}, J=1.5 \mathrm{~Hz}, 1 \mathrm{H})$ & $5.86(\mathrm{~d}, J=1.7 \mathrm{~Hz}, 1 \mathrm{H})$ & 132.3 & 132.18 \\
\hline $5.79(\mathrm{ddd}, J=5.9,5.2,2.5 \mathrm{~Hz} .1 \mathrm{H})$ & $5.76-5.79(\mathrm{~m}, 1 \mathrm{H})$ & 131.9 & 131.7 \\
\hline $5.52(\mathrm{ddd}, J=5.9,4.4,2.1 \mathrm{~Hz}, 1 \mathrm{H})$ & $5.49-5.53(\mathrm{~m}, 1 \mathrm{H})$ & 128.7 & 128.6 \\
\hline 3.87 (br s, $1 \mathrm{H})$ & $3.85-3.87(\mathrm{~m}, 1 \mathrm{H})$ & 110.8 & 110.8 \\
\hline $3.18(\mathrm{ddd}, J=14.0,12.6,7.4 \mathrm{~Hz}, 1 \mathrm{H})$ & $3.18(\mathrm{ddd}, J=14.0,12.5,7.4 \mathrm{~Hz}, 1 \mathrm{H})$ & 109.8 & 109.7 \\
\hline $3.07(\mathrm{ddd}, J=9.5,9.0,4.4 \mathrm{~Hz}, 1 \mathrm{H})$ & $3.06(\mathrm{dt}, J=9.2,4.3 \mathrm{~Hz}, 1 \mathrm{H})$ & 100.7 & 100.6 \\
\hline $2.91(\mathrm{ddd}, J=12.6,11.7,6.8 \mathrm{~Hz}, 1 \mathrm{H})$ & $2.90(\mathrm{dt}, J=12.0,6.9 \mathrm{~Hz}, 1 \mathrm{H})$ & 68.0 & 67.9 \\
\hline $2.74(\mathrm{ddd}, J=17.8,4.4,2.5 \mathrm{~Hz}, 1 \mathrm{H})$ & $2.71-2.75(\mathrm{~m}, 1 \mathrm{H})$ & 62.4 & 62.3 \\
\hline $2.54(\mathrm{dd}, J=11.7,7.4 \mathrm{~Hz}, 1 \mathrm{H})$ & $2.53(\mathrm{dd}, J=11.4,7.4 \mathrm{~Hz}, 1 \mathrm{H})$ & 53.5 & 53.4 \\
\hline $2.39(\mathrm{ddd}, J=9.9,9.5,6.2 \mathrm{~Hz}, 1 \mathrm{H})$ & $2.38(\mathrm{dt}, J=9.9,6.1 \mathrm{~Hz}, 1 \mathrm{H})$ & 49.0 & 48.9 \\
\hline $2.32(\mathrm{dd}, J=14.0,6.8 \mathrm{~Hz}, 1 \mathrm{H})$ & $2.31(\mathrm{dd}, J=14.2,6.6 \mathrm{~Hz}, 1 \mathrm{H})$ & 43.3 & 43.2 \\
\hline $1.92-2.05(\mathrm{~m}, 3 \mathrm{H})$ & $1.95-1.99(\mathrm{~m}, 1 \mathrm{H})$ & 34.7 & 34.6 \\
\hline $1.66-1.81(\mathrm{~m}, 2 \mathrm{H})$ & $1.92-1.95(\mathrm{~m}, 2 \mathrm{H})$ & 30.7 & 30.5 \\
\hline & $1.73-1.79(\mathrm{~m}, 1 \mathrm{H})$ & 19.9 & 19.8 \\
\hline & $1.67-1.73(\mathrm{~m}, 1 \mathrm{H})$ & & \\
\hline
\end{tabular}

${ }^{a}$ Measured at $270 \mathrm{MHz} .{ }^{b}$ Measured at $800 \mathrm{MHz} .{ }^{c}$ Unidentified frequency. ${ }^{d}$ Measured at $200 \mathrm{MHz}$. 


\section{B. Chiral HPLC Chromatograms of Compound 20}

We determined enantiomeric excess of compound 20 by chiral HPLC. The chromatogram was compared with the chromatogram obtained from rac-20 which was prepared with ( \pm )-3-butyn 2-ol.

HPLC condition: CHIRALCEL OD-H $(0.46 \times 25 \mathrm{~cm}, 5 \mu \mathrm{m})$, hexane/ethanol $=97: 3,30 \mathrm{~min}$, flow rate $1.0 \mathrm{~mL} / \mathrm{min}$, $\lambda=290 \mathrm{~nm}$

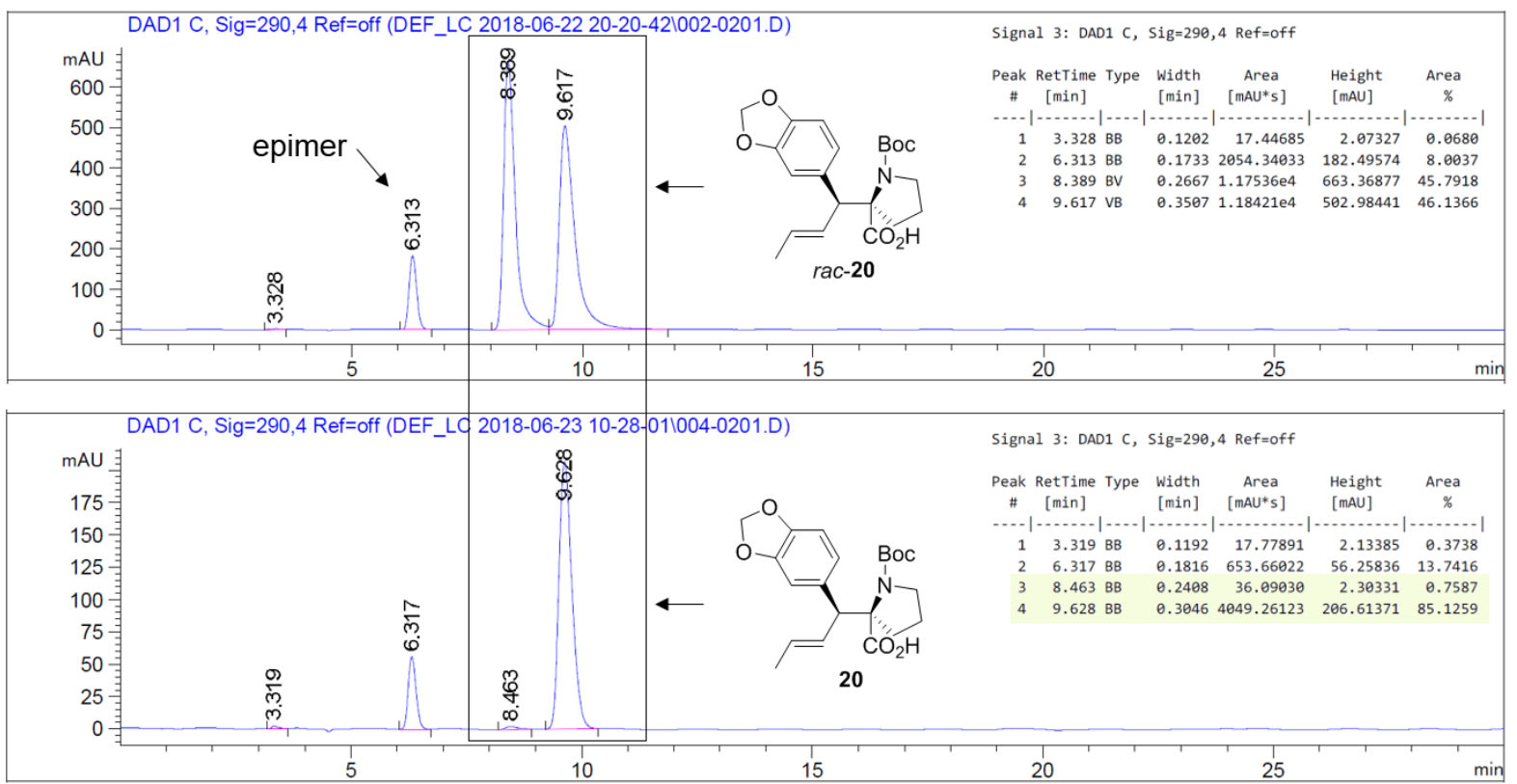


C. Copies of Spectra $\left({ }^{1} \mathrm{H}\right.$ NMR, ${ }^{13} \mathrm{C}$ NMR)

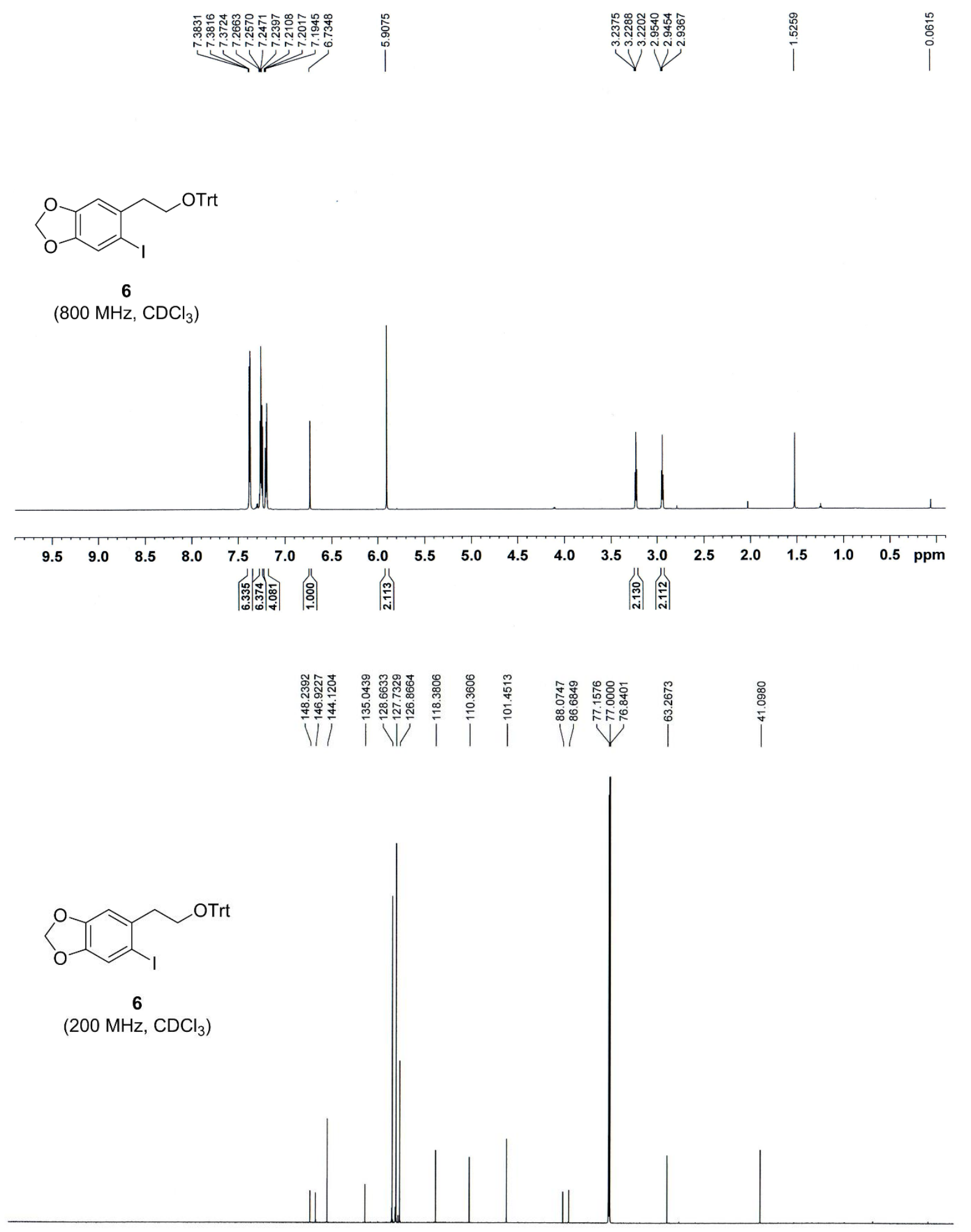

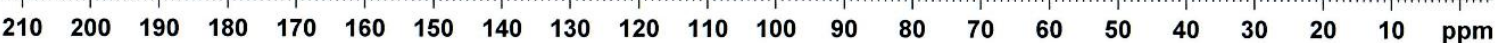




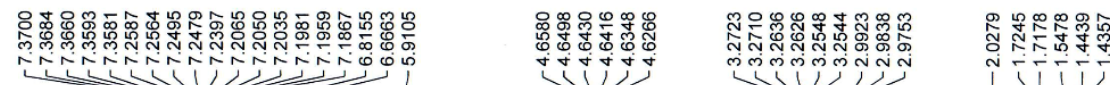
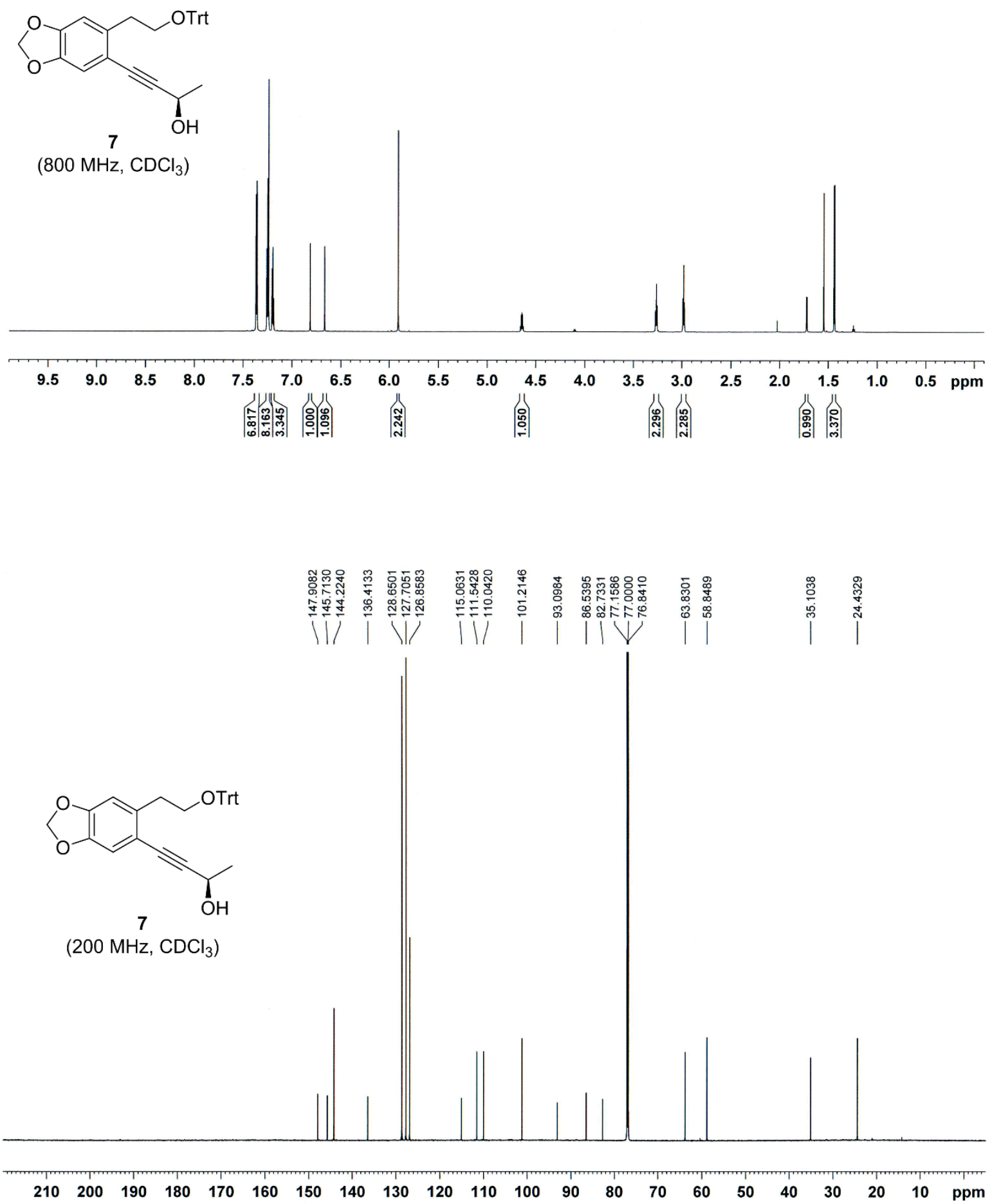


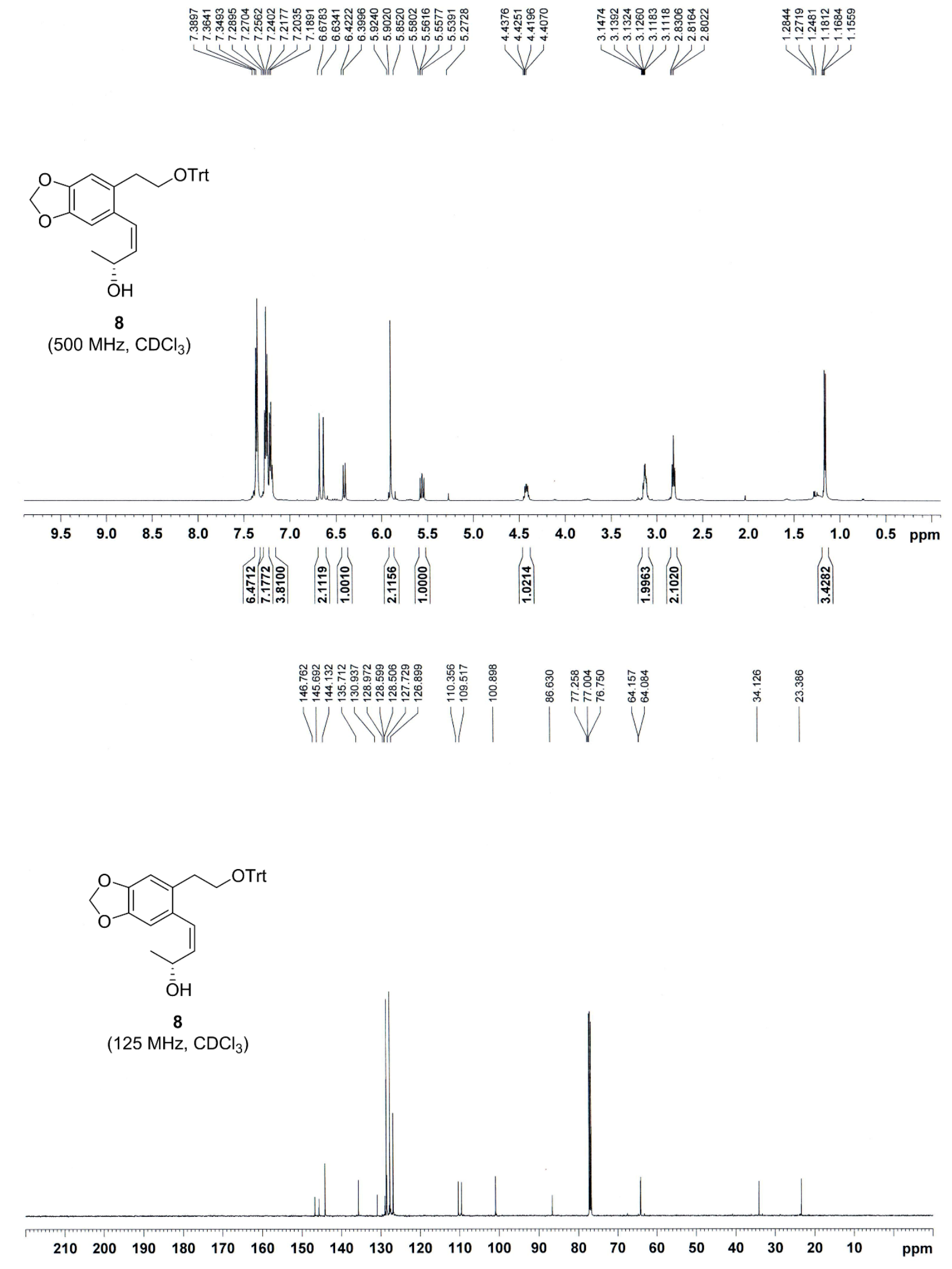



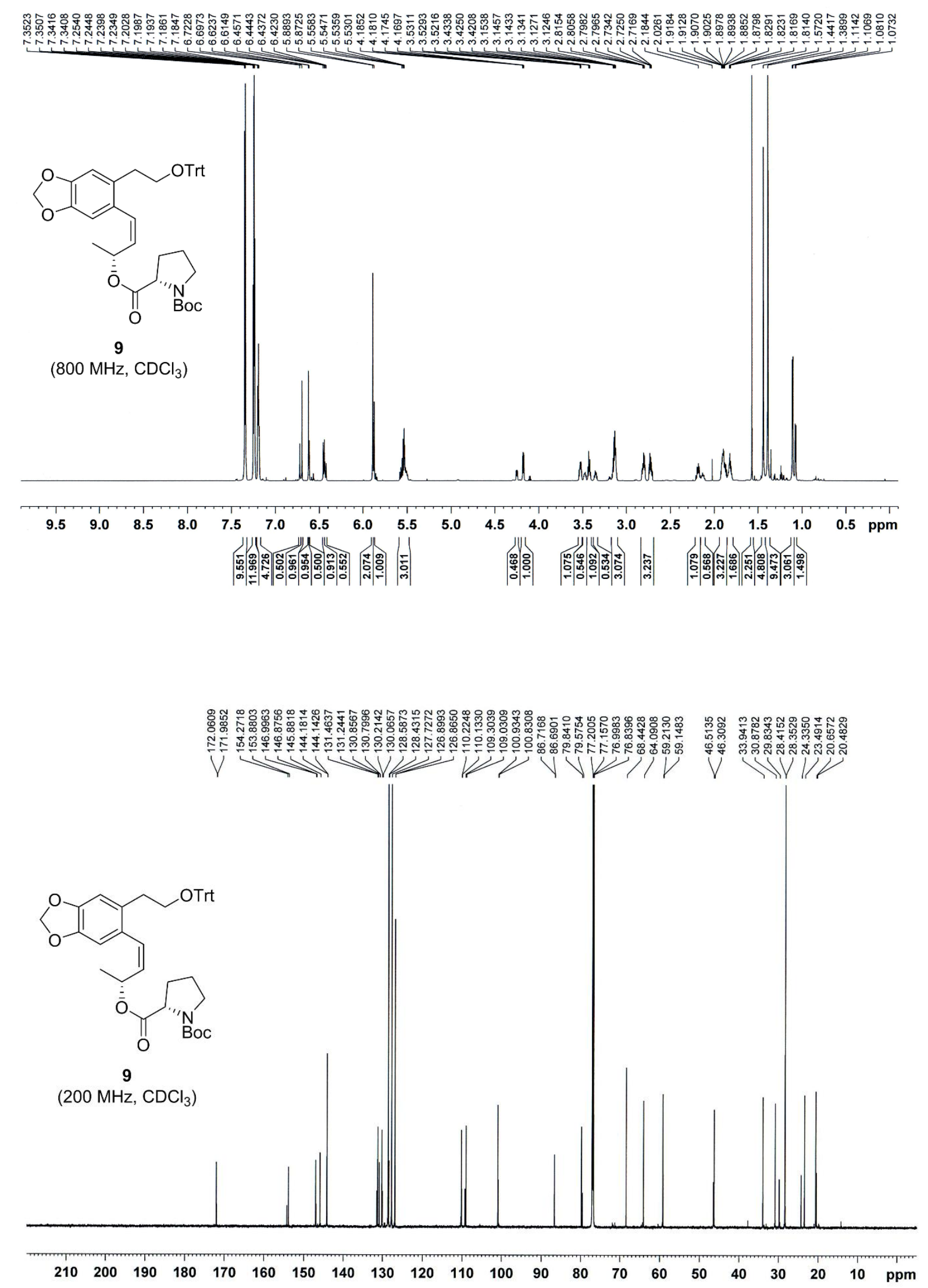

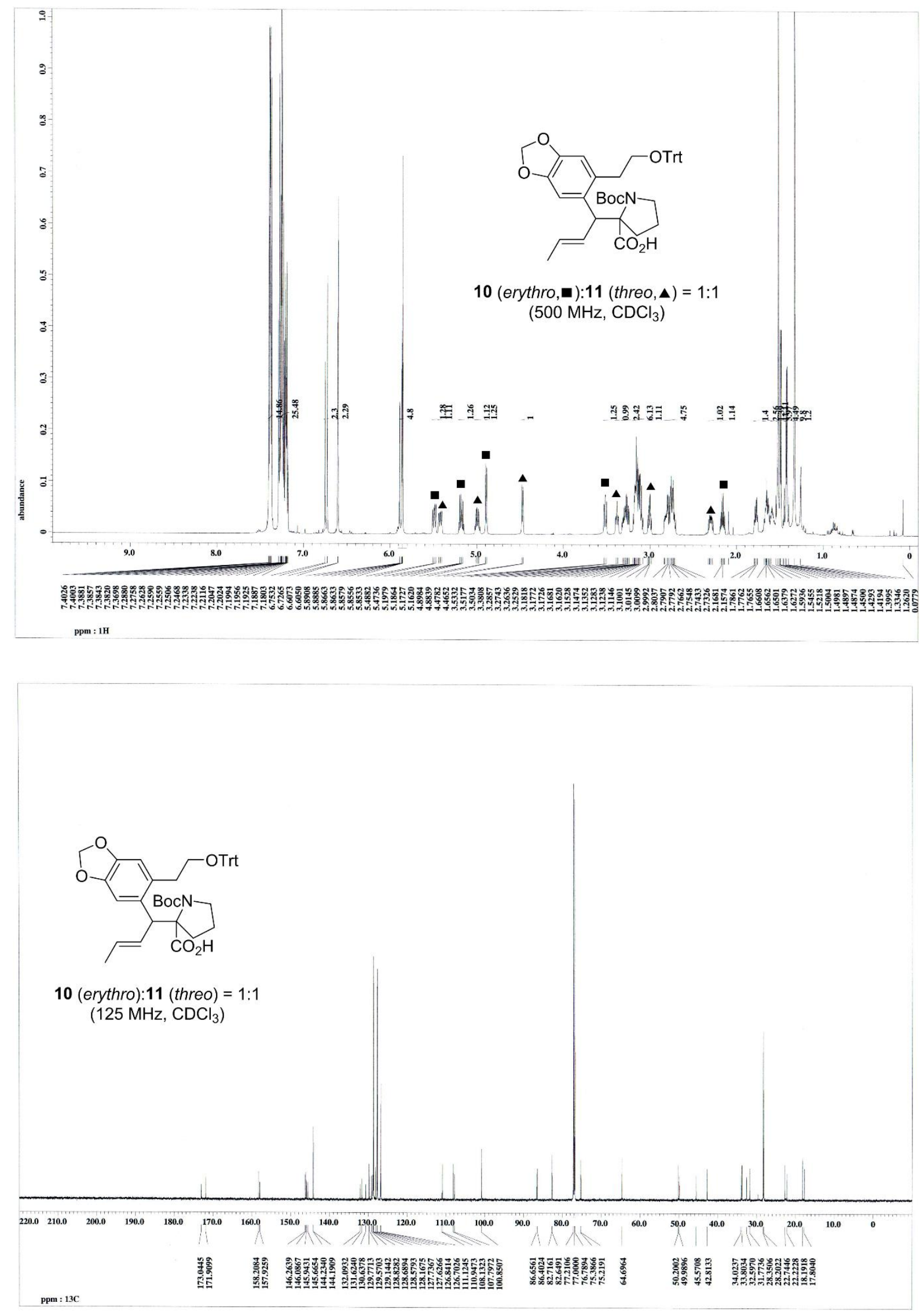

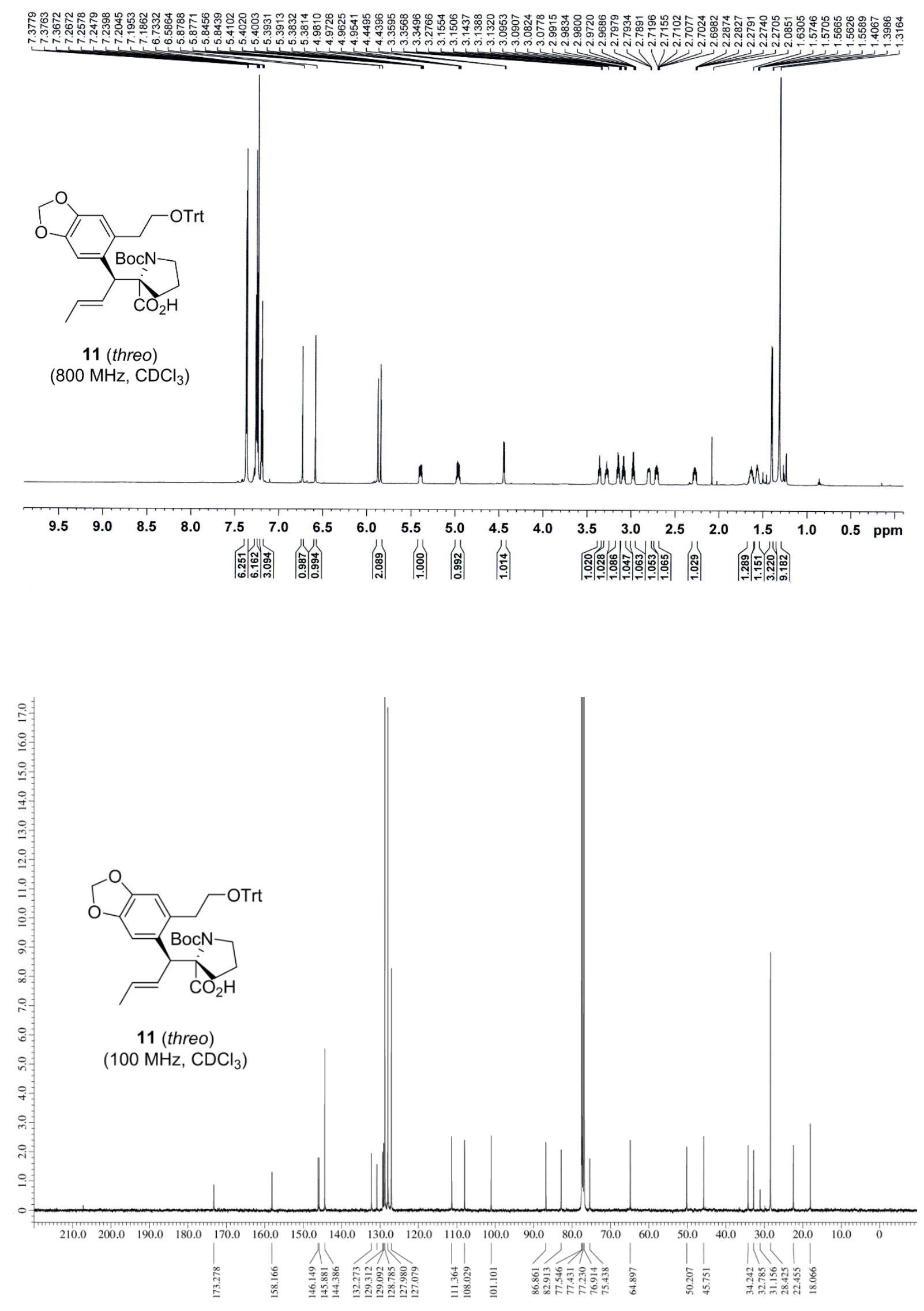


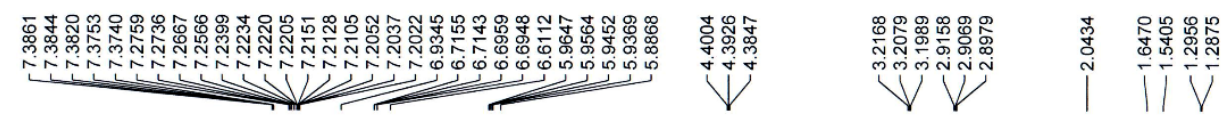
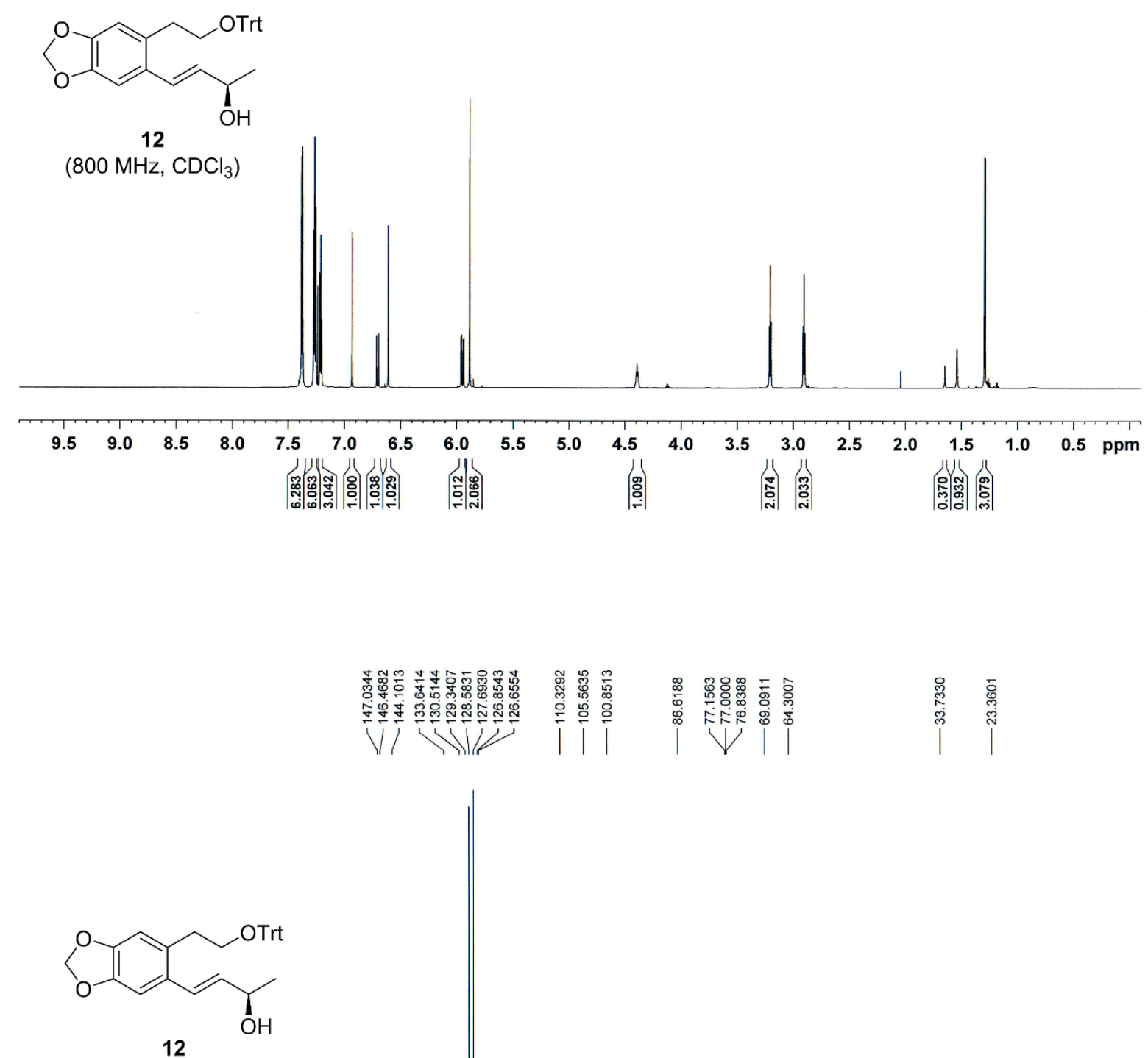

$\left(200 \mathrm{MHz}, \mathrm{CDCl}_{3}\right)$
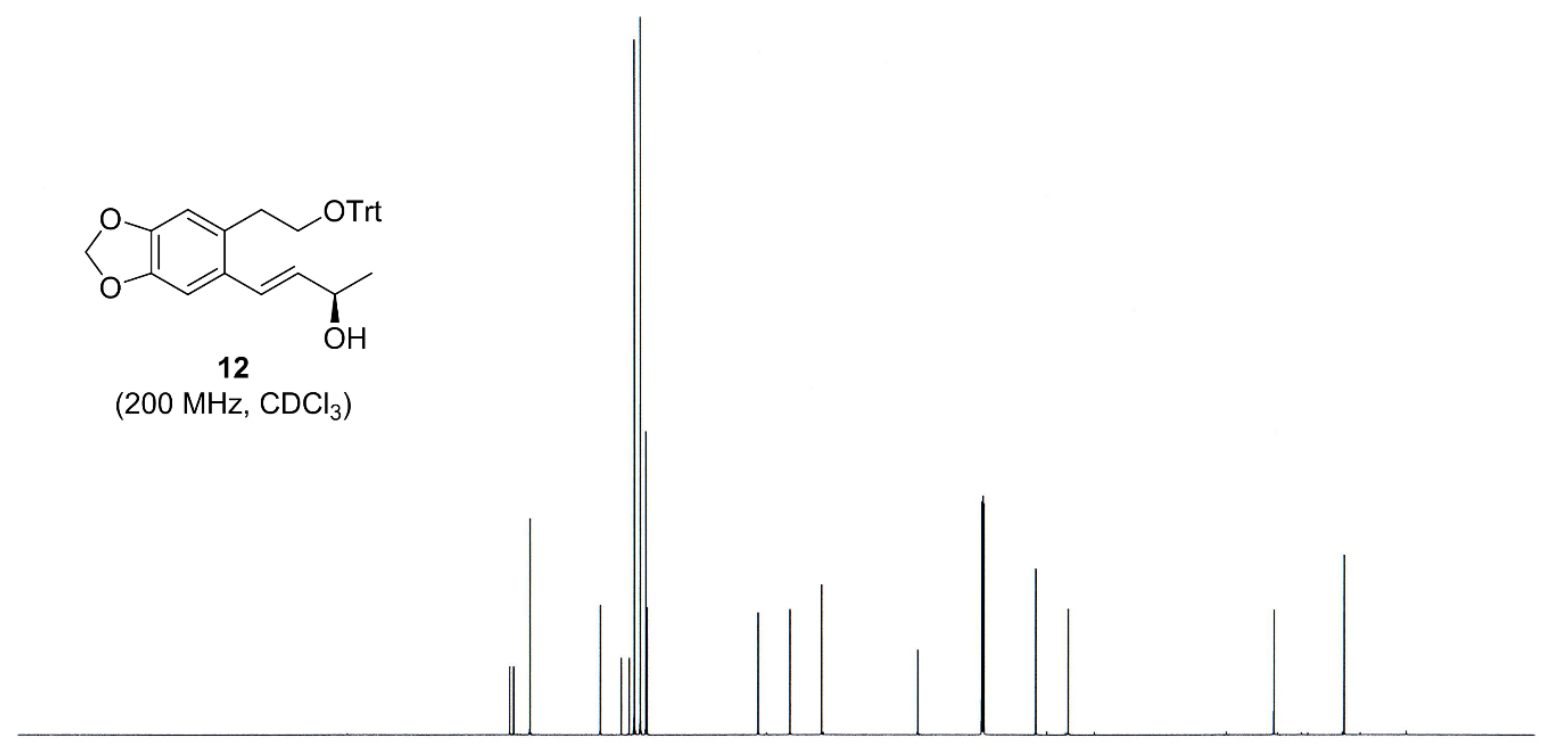

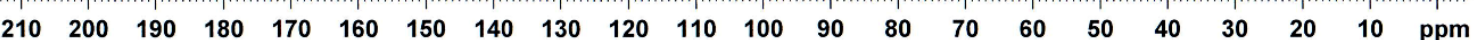




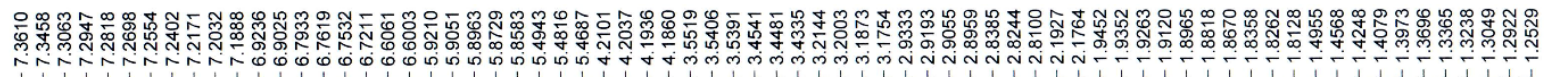<smiles>CCCOCCc1cc2c(cc1/C=C/C(C)OC(=O)C1CCCN1C(=O)OCc1ccccc1)OCO2</smiles>

$\left(500 \mathrm{MHz}, \mathrm{CDCl}_{3}\right)$

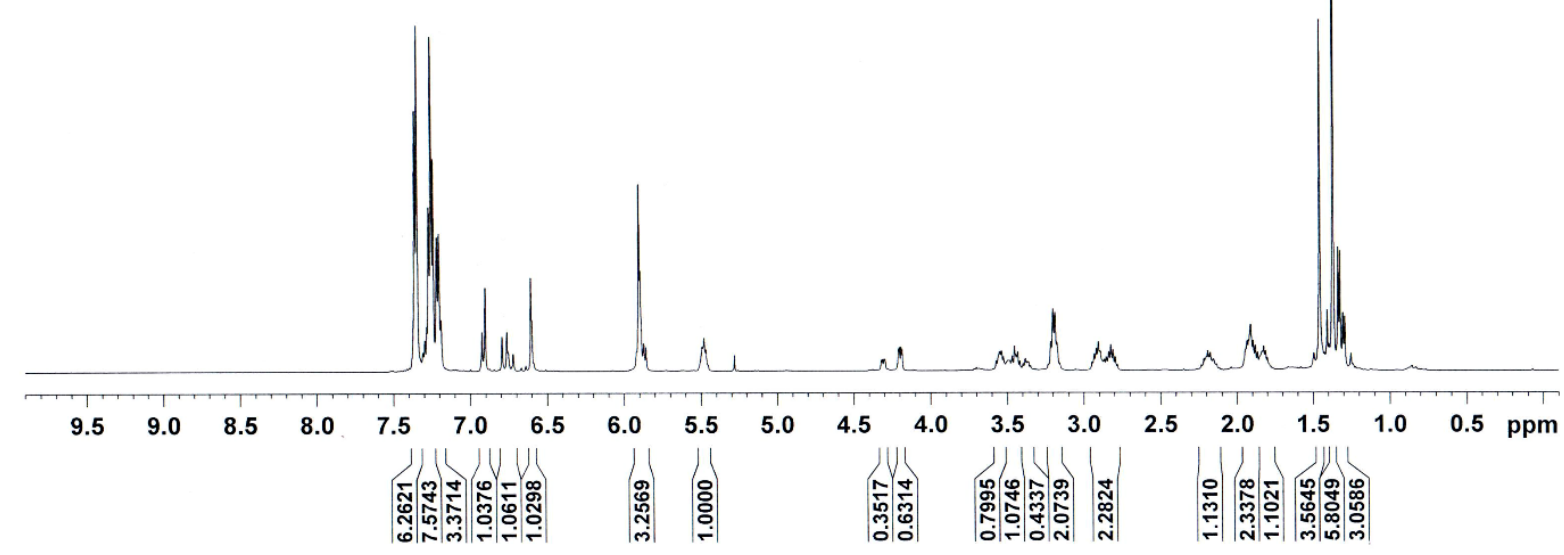

13

$\left(200 \mathrm{MHz}, \mathrm{CDCl}_{3}\right)$<smiles>CC(C)CCCc1cc2c(cc1/C=C/C(C)OC(=O)C1CCCN1C(=O)O)OCO2</smiles>

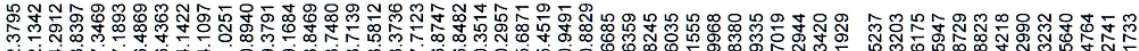

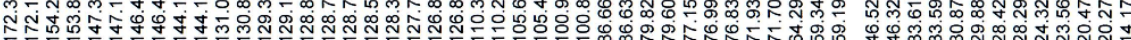

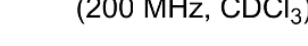

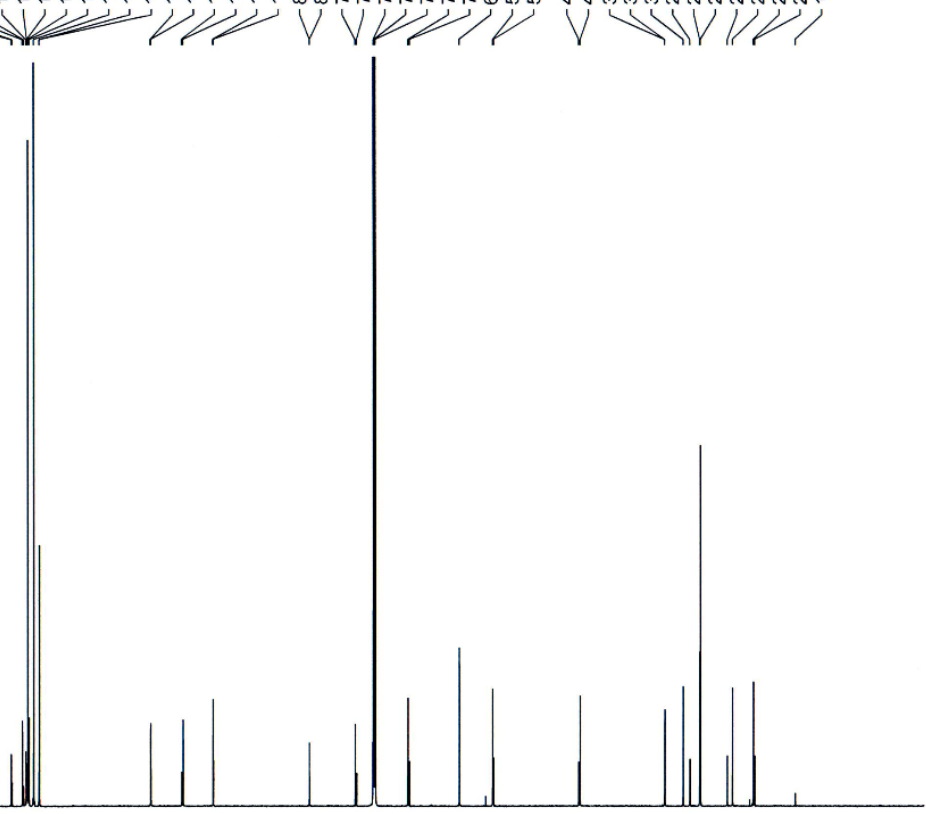

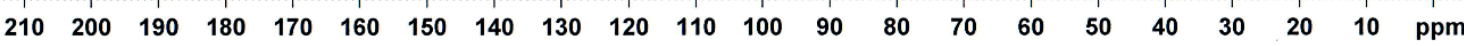


<smiles>[15NH]N1CCC[C]1C(=O)O</smiles>

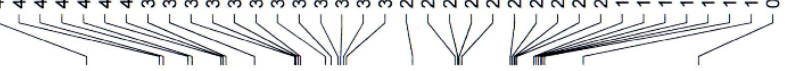

14

(500 MHz, $\left.\mathrm{CD}_{3} \mathrm{OD}\right)$
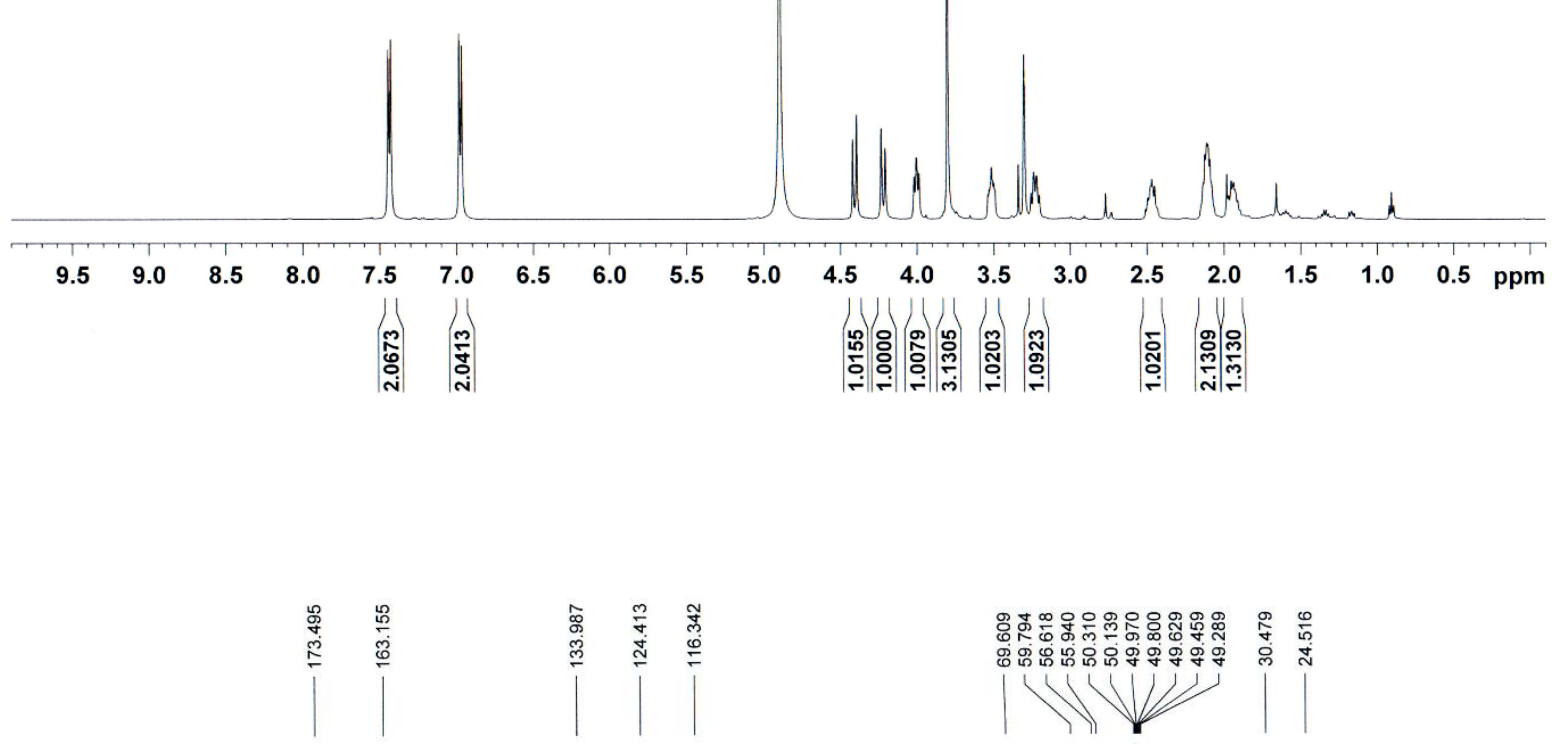

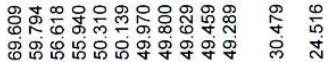

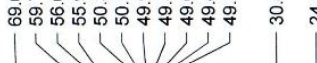<smiles>CS(=O)(=O)N1CCC[C@H]1C(=O)O</smiles>

14

(125 MHz, $\left.\mathrm{CD}_{3} \mathrm{OD}\right)$

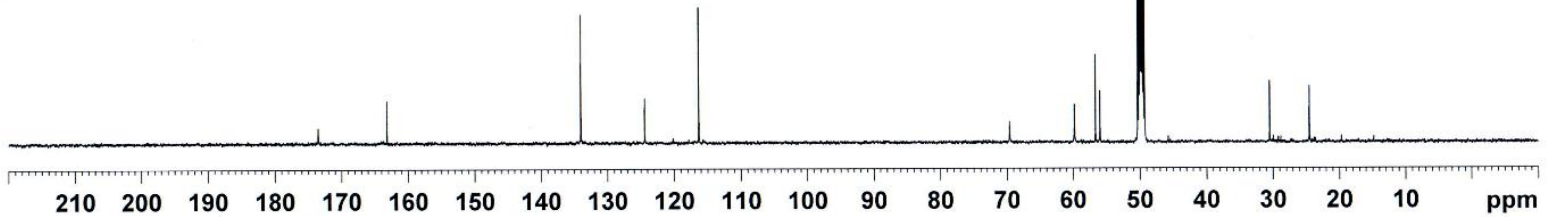




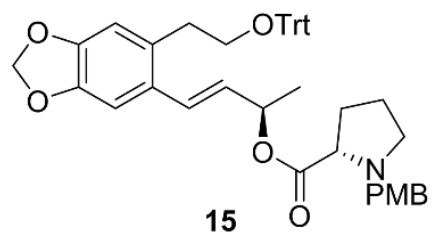

(500 MHz, $\mathrm{CDCl}_{3}$ )
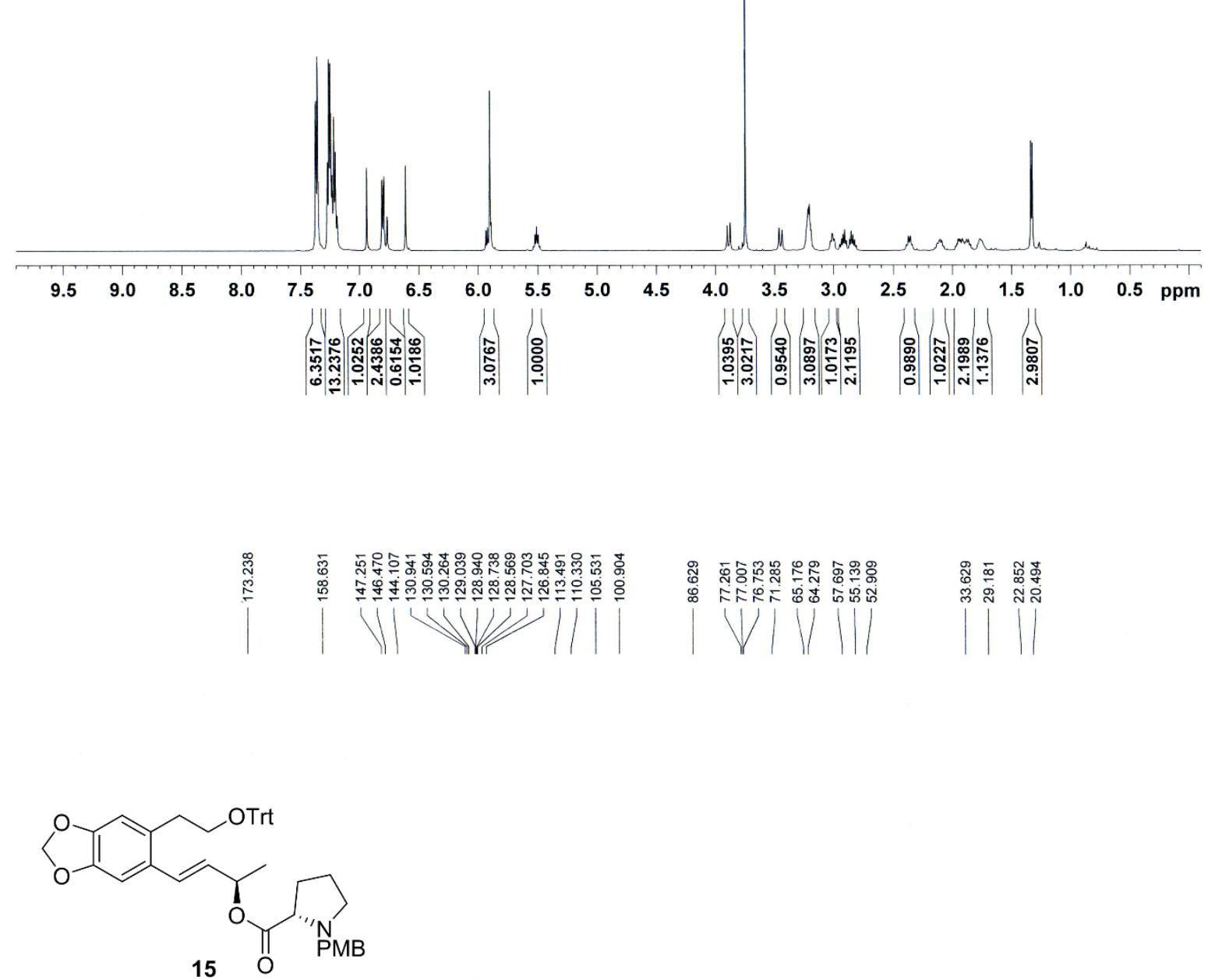

$\left(125 \mathrm{MHz}, \mathrm{CDCl}_{3}\right)$

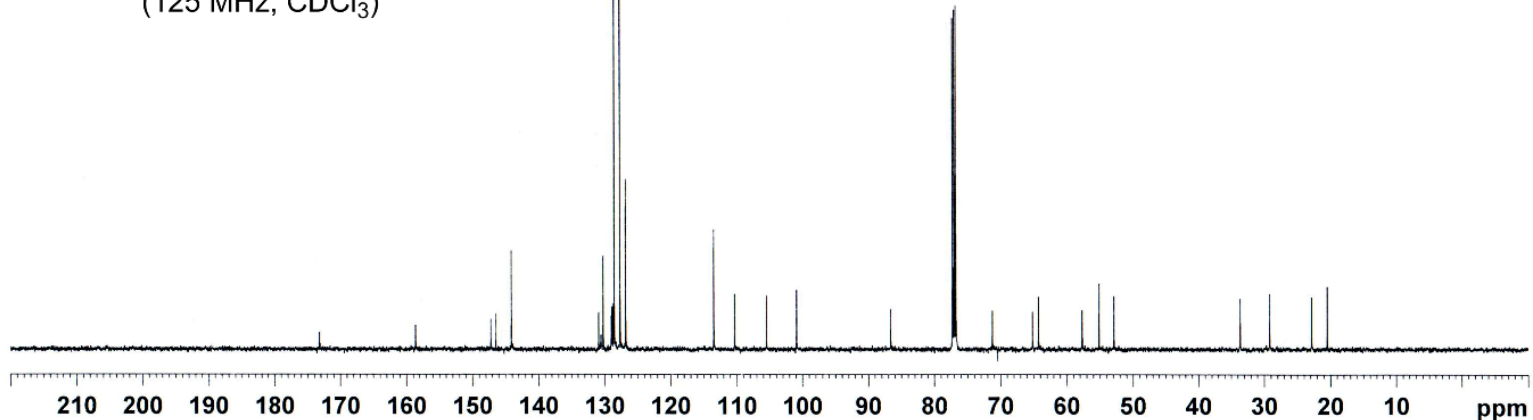



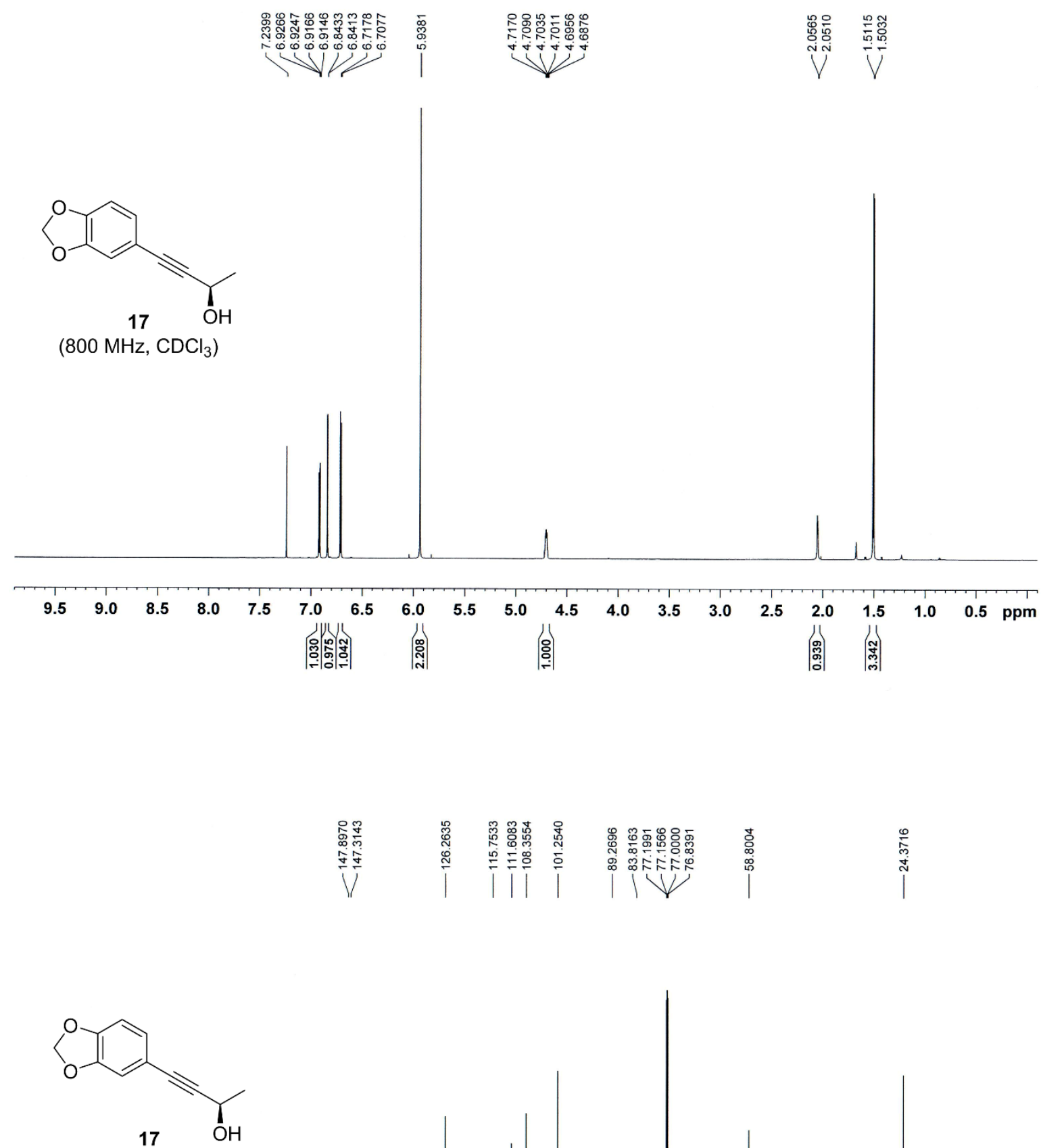

$\left(200 \mathrm{MHz}, \mathrm{CDCl}_{3}\right)$

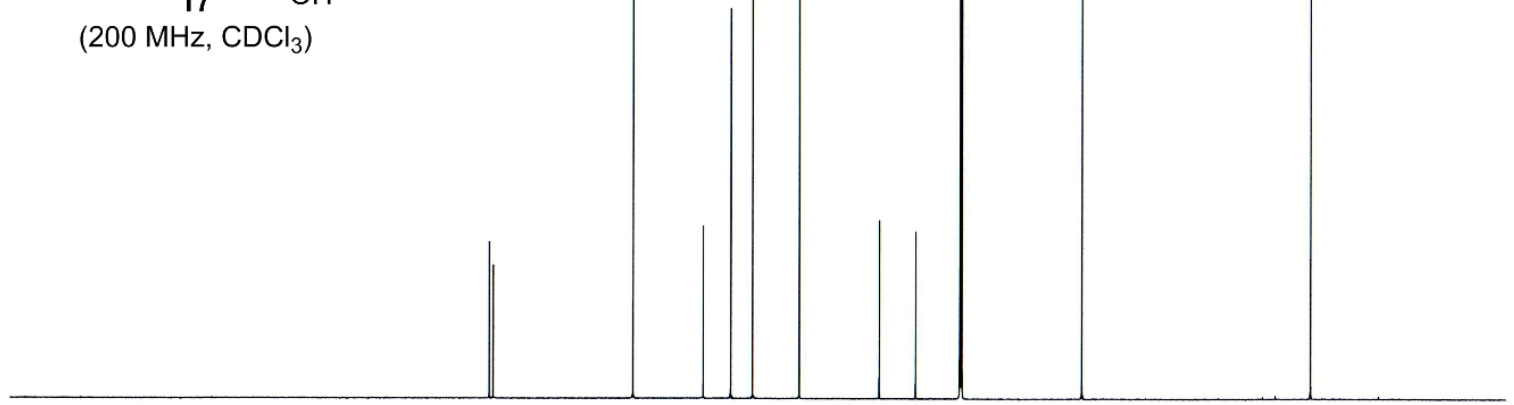

$\begin{array}{lllllllllllllllllllllll}210 & 200 & 190 & 180 & 170 & 160 & 150 & 140 & 130 & 120 & 110 & 100 & 90 & 80 & 70 & 60 & 50 & 40 & 30 & 20 & 10 & \mathrm{ppm}\end{array}$ 


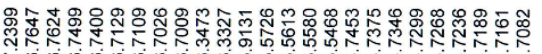

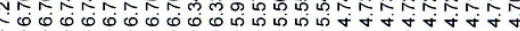

Vij<smiles>C[C@H](O)/C=C\c1ccc2c(c1)OCO2</smiles>

18

$\left(800 \mathrm{MHz}, \mathrm{CDCl}_{3}\right)$

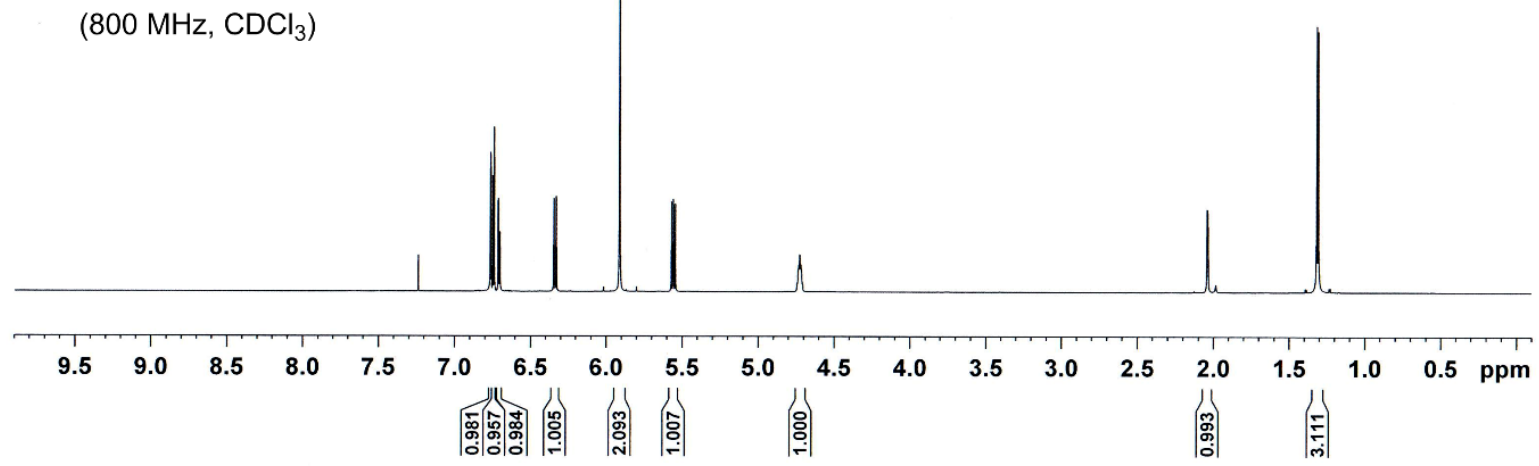<smiles>C[C@H](O)/C=C\c1ccc2c(c1)OCO2</smiles>

18

$\left(200 \mathrm{MHz}, \mathrm{CDCl}_{3}\right)$

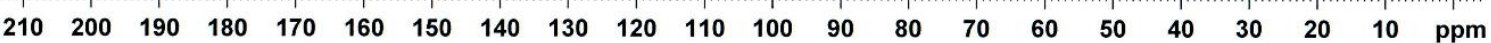




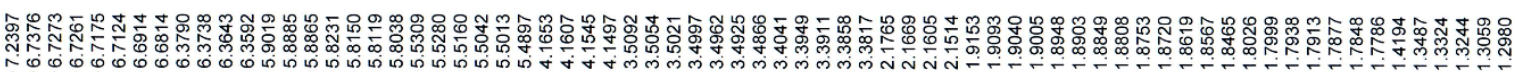

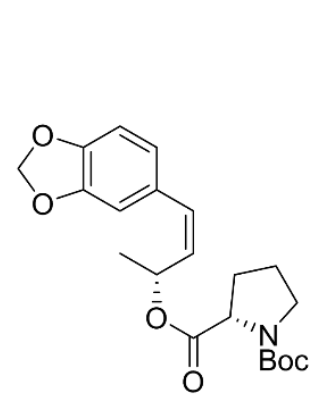

19

(800 MHz, $\mathrm{CDCl}_{3}$ )

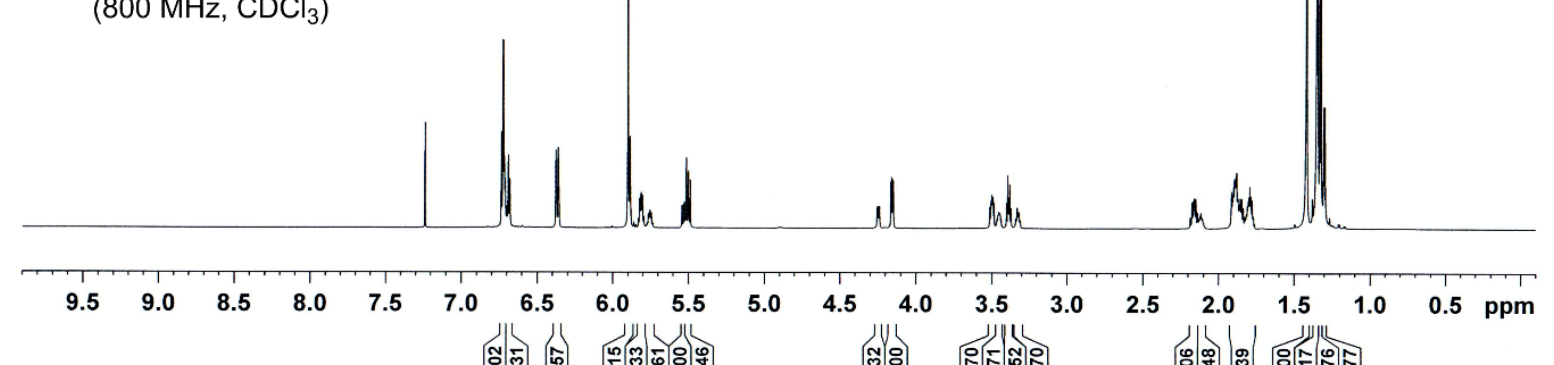

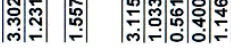<smiles></smiles>

19

$\left(200 \mathrm{MHz}, \mathrm{CDCl}_{3}\right)$

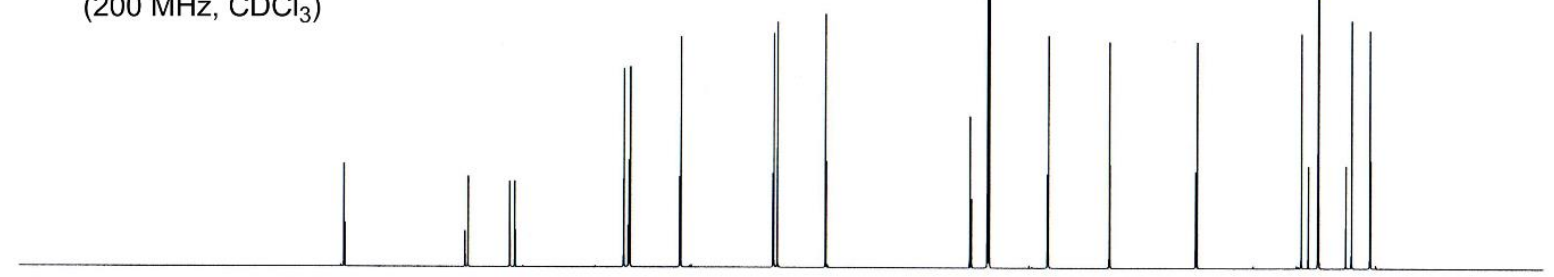

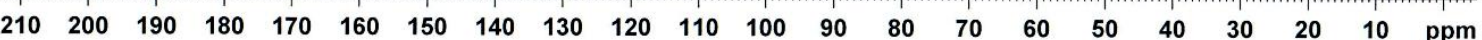




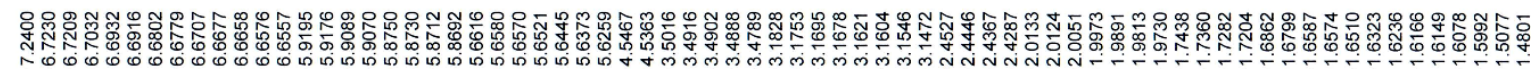
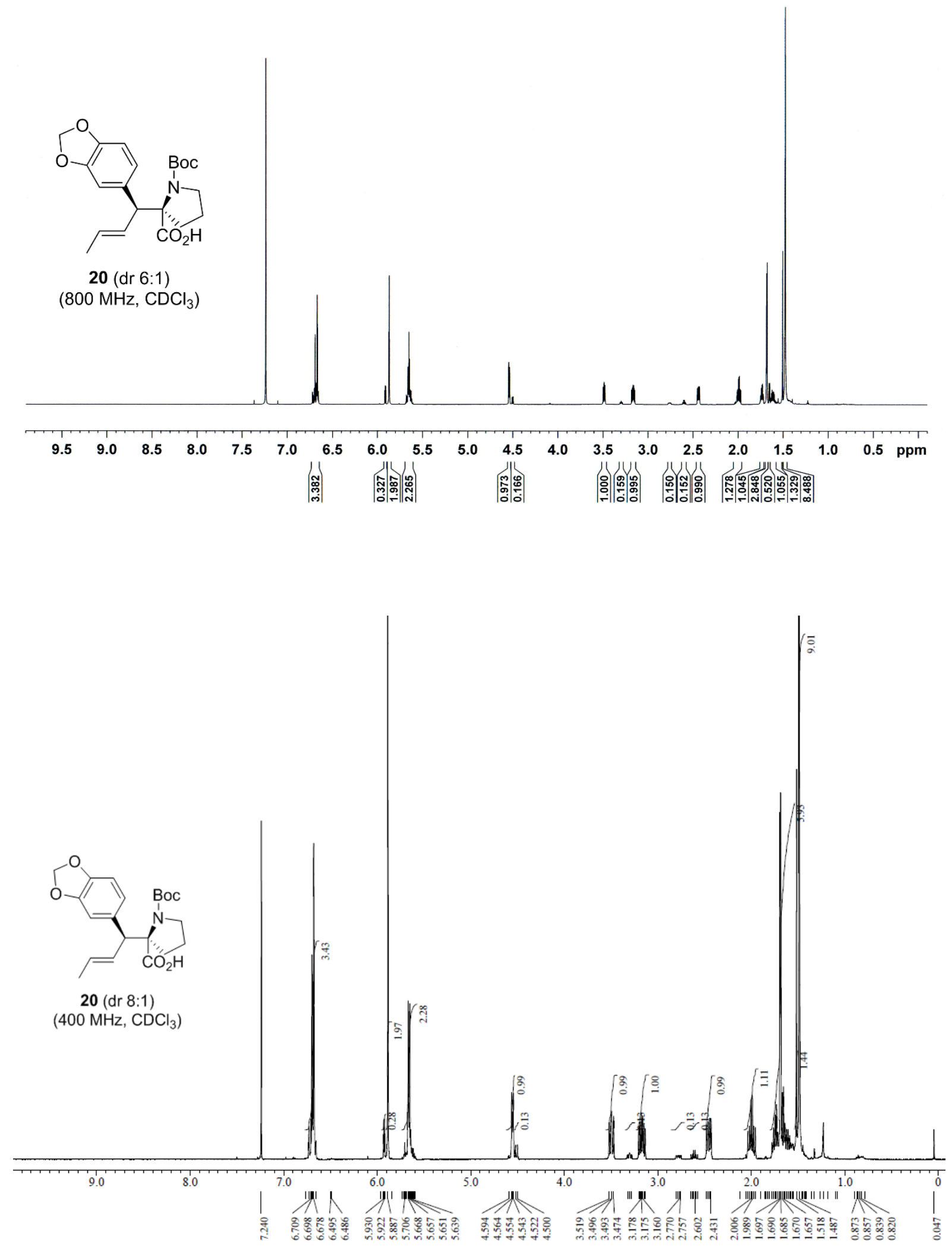


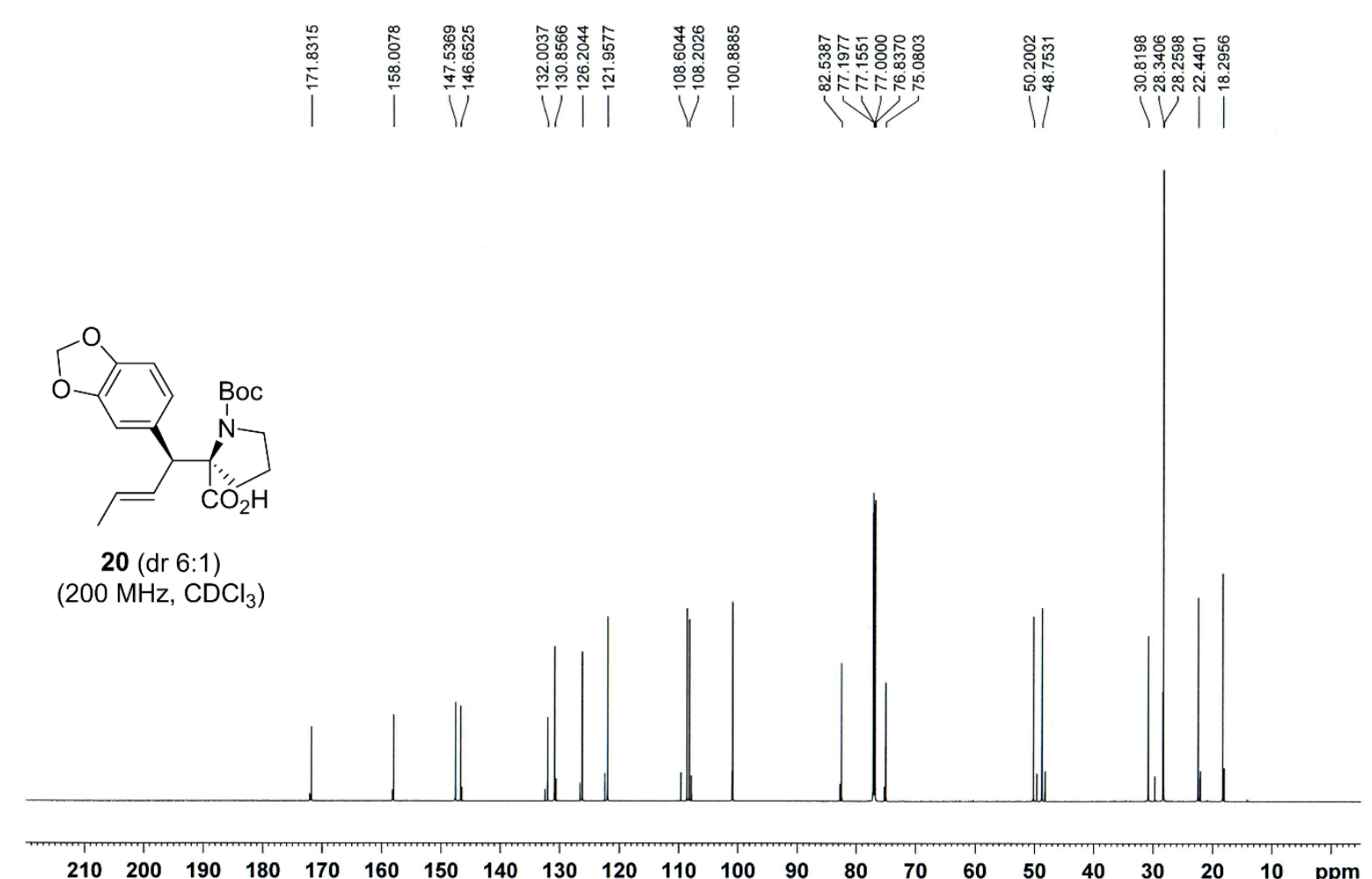

$\begin{array}{llllllllllllllllllllll}210 & 200 & 190 & 180 & 170 & 160 & 150 & 140 & 130 & 120 & 110 & 100 & 90 & 80 & 70 & 60 & 50 & 40 & 30 & 20 & 10 & \text { ppm }\end{array}$

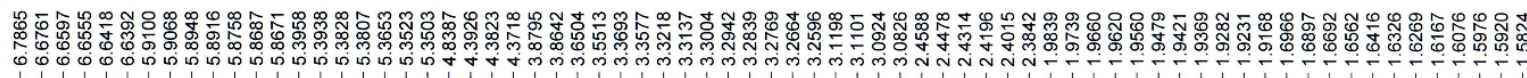

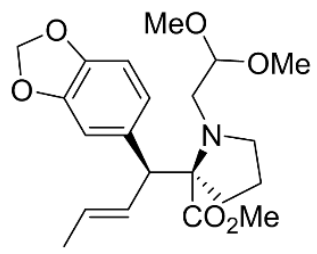

21

$\left(500 \mathrm{MHz}, \mathrm{CD}_{3} \mathrm{OD}\right)$

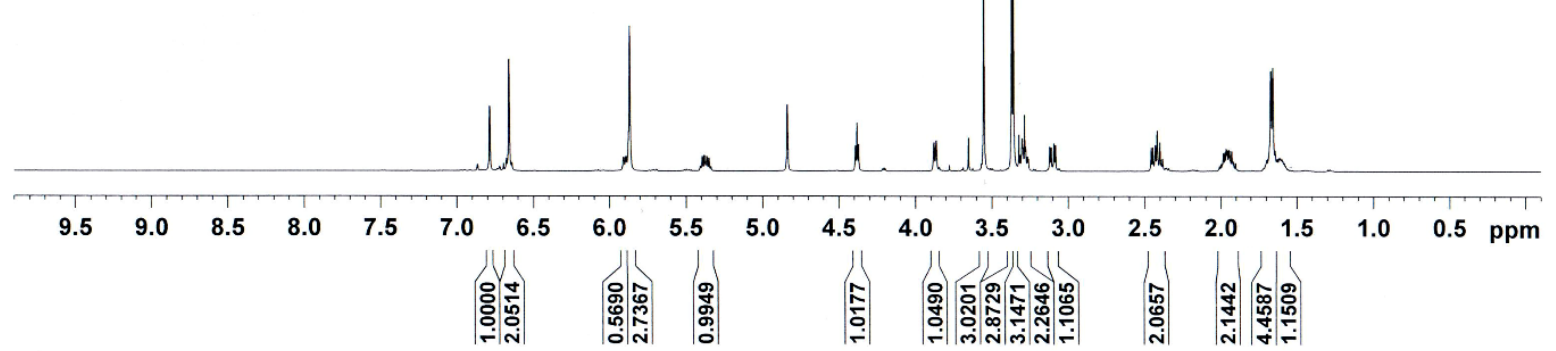



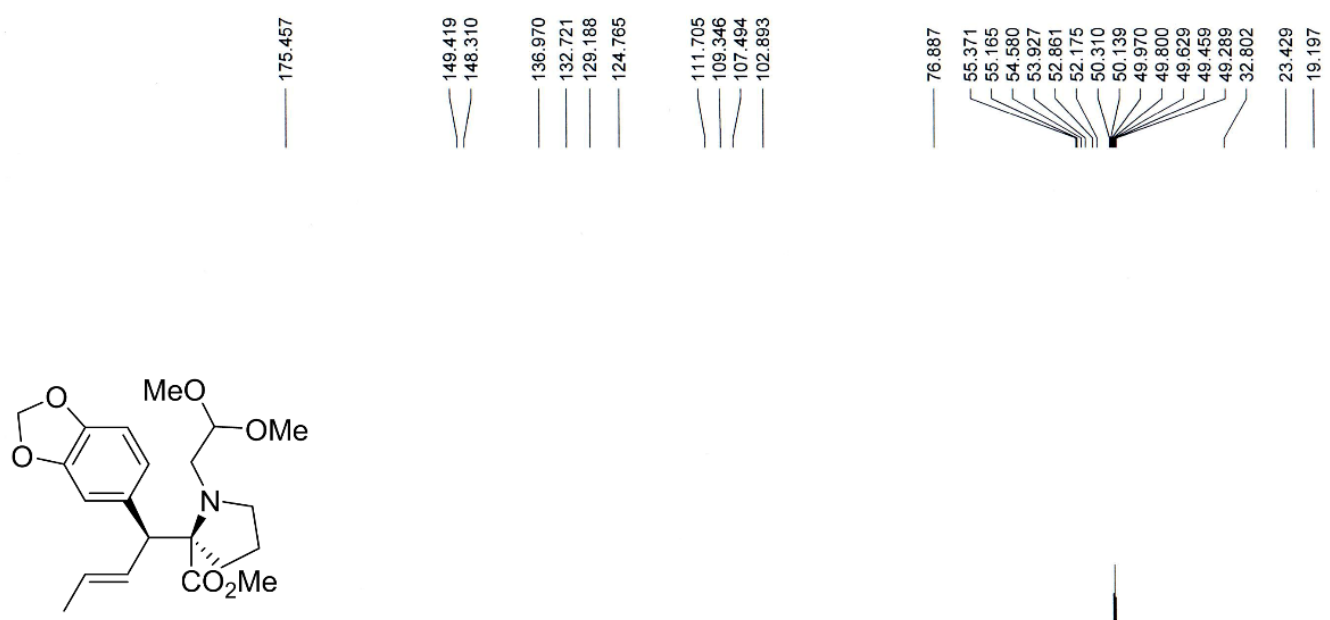

21

$\left(125 \mathrm{MHz}, \mathrm{CD}_{3} \mathrm{OD}\right)$

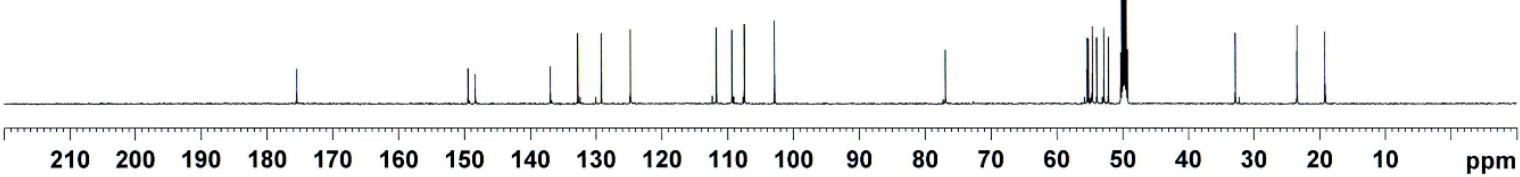

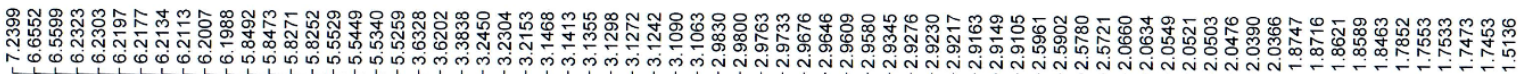

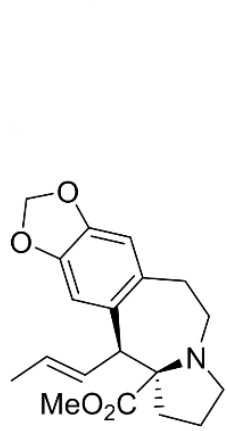

22

$\left(800 \mathrm{MHz}, \mathrm{CDCl}_{3}\right)$

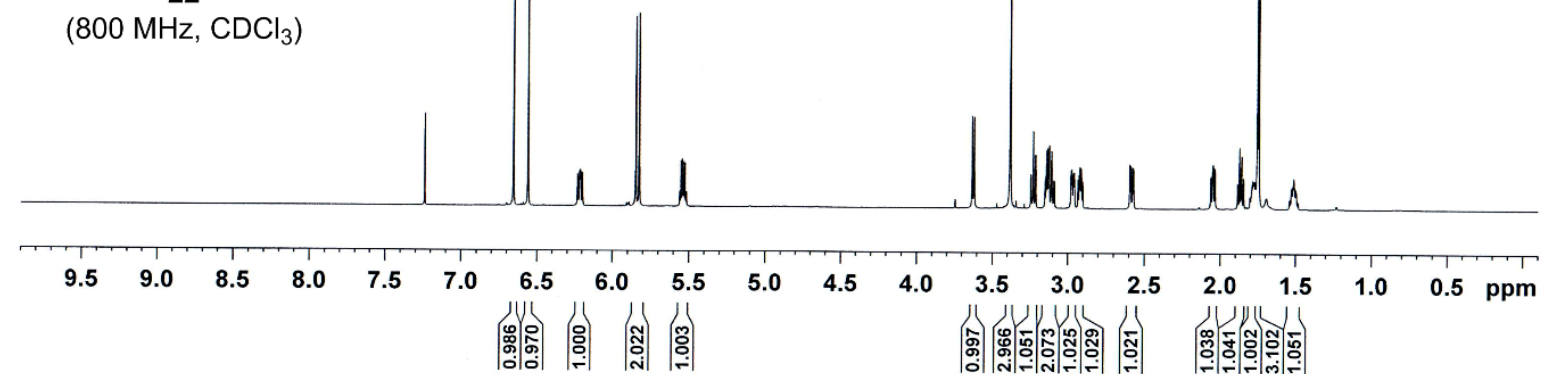




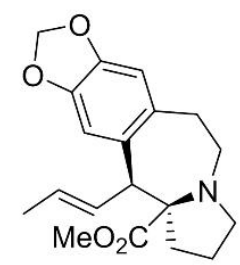

22

$\left(200 \mathrm{MHz}, \mathrm{CDCl}_{3}\right)$

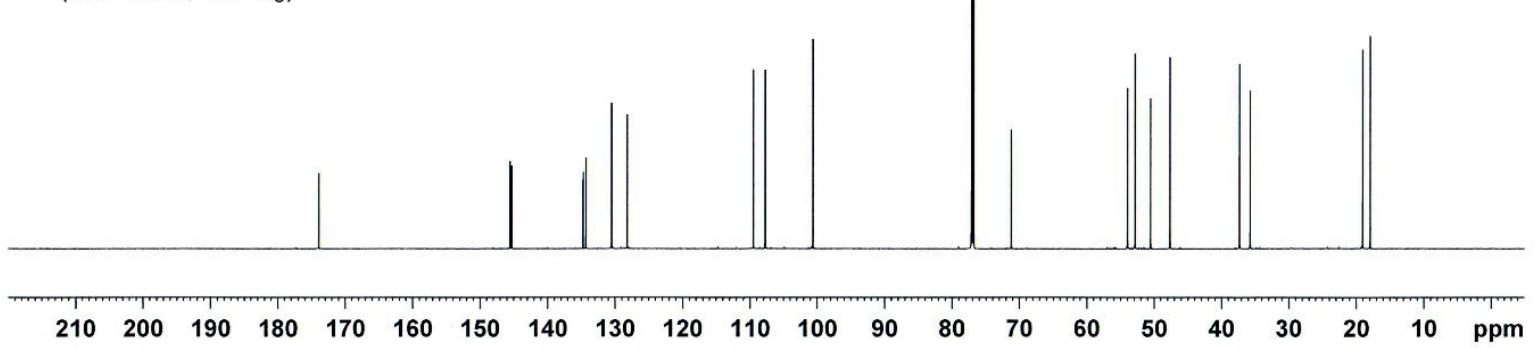

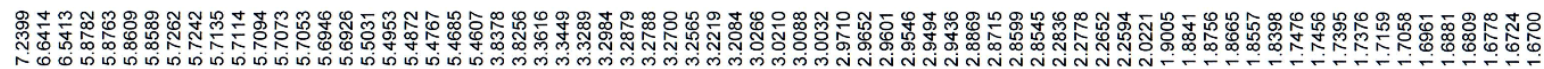

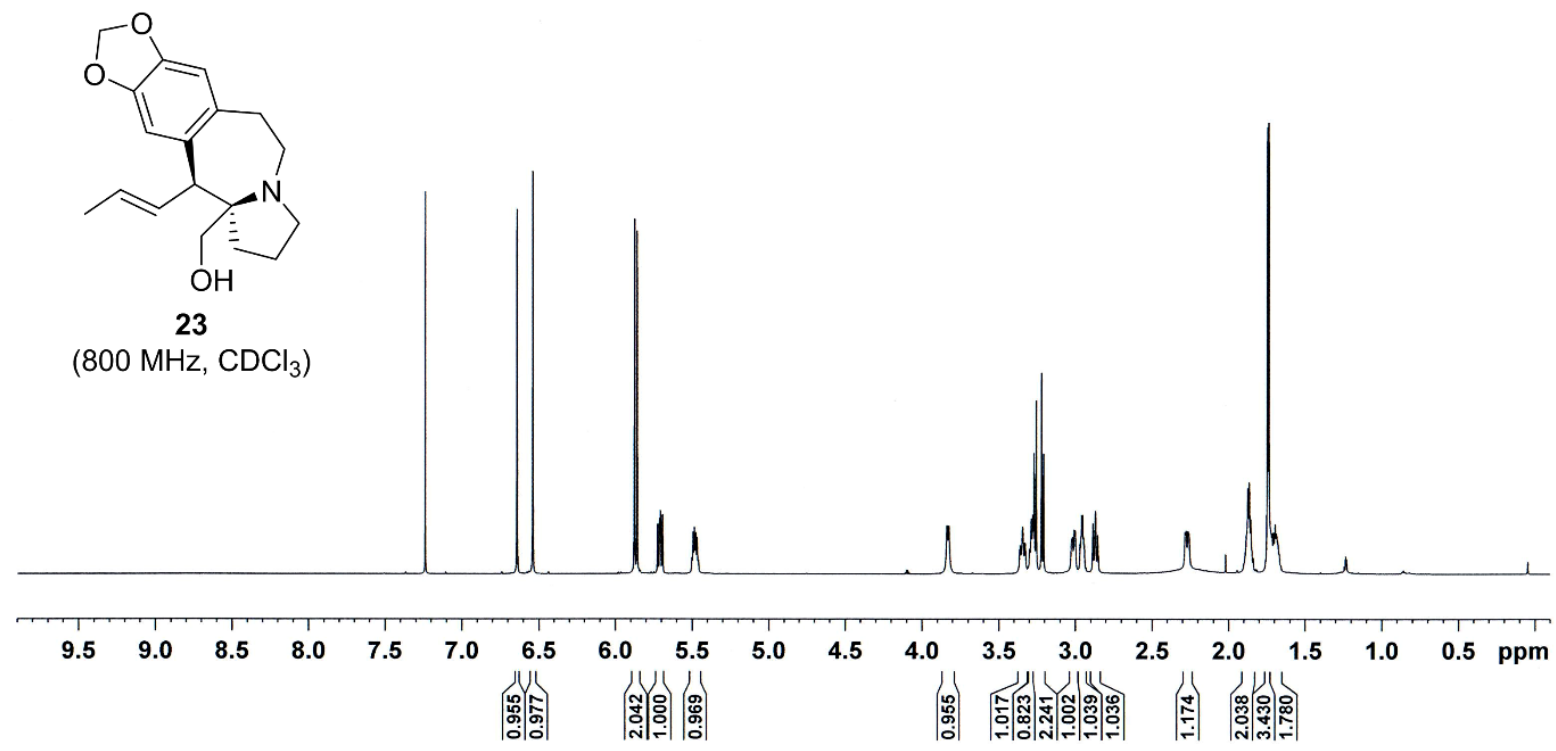



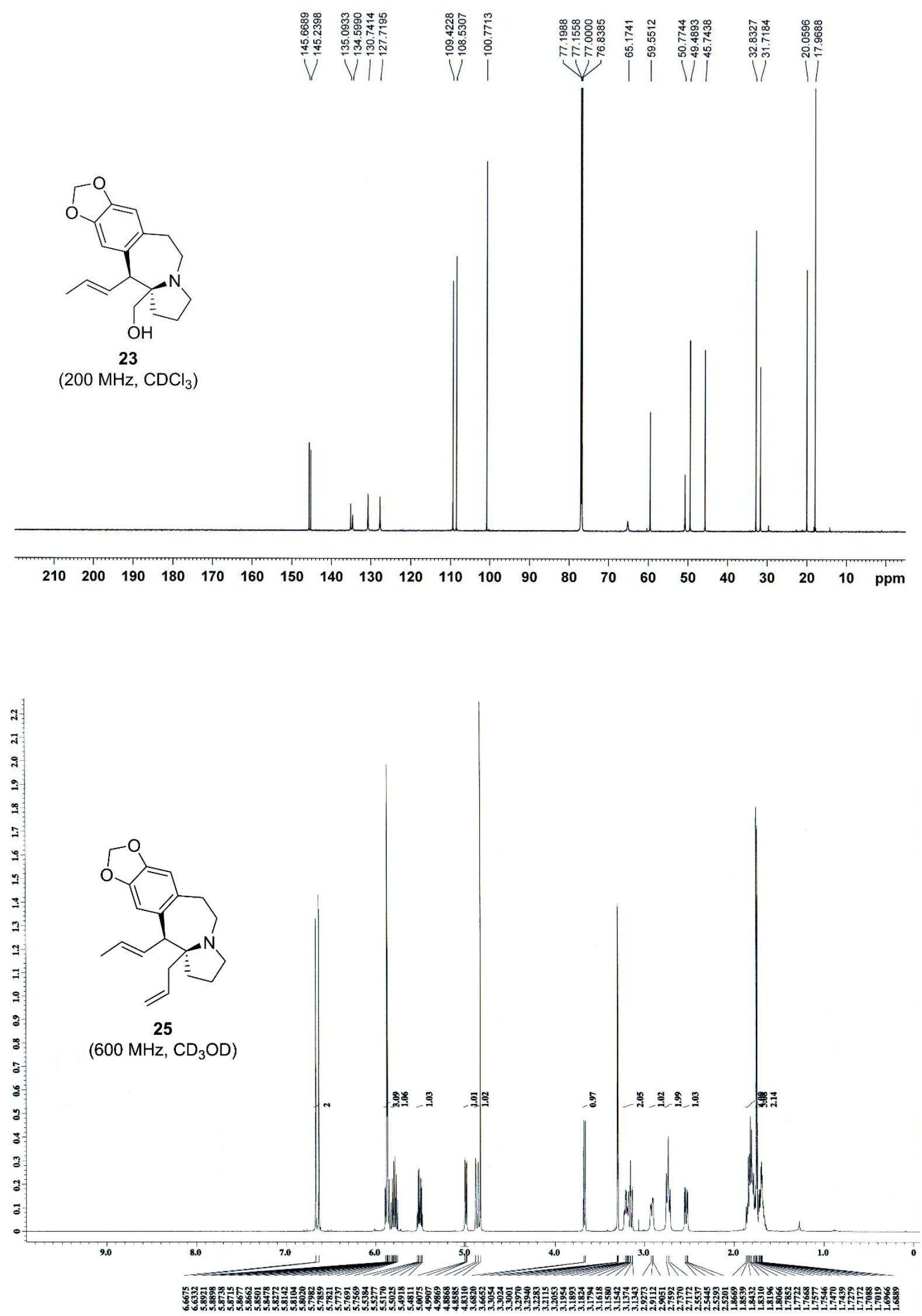


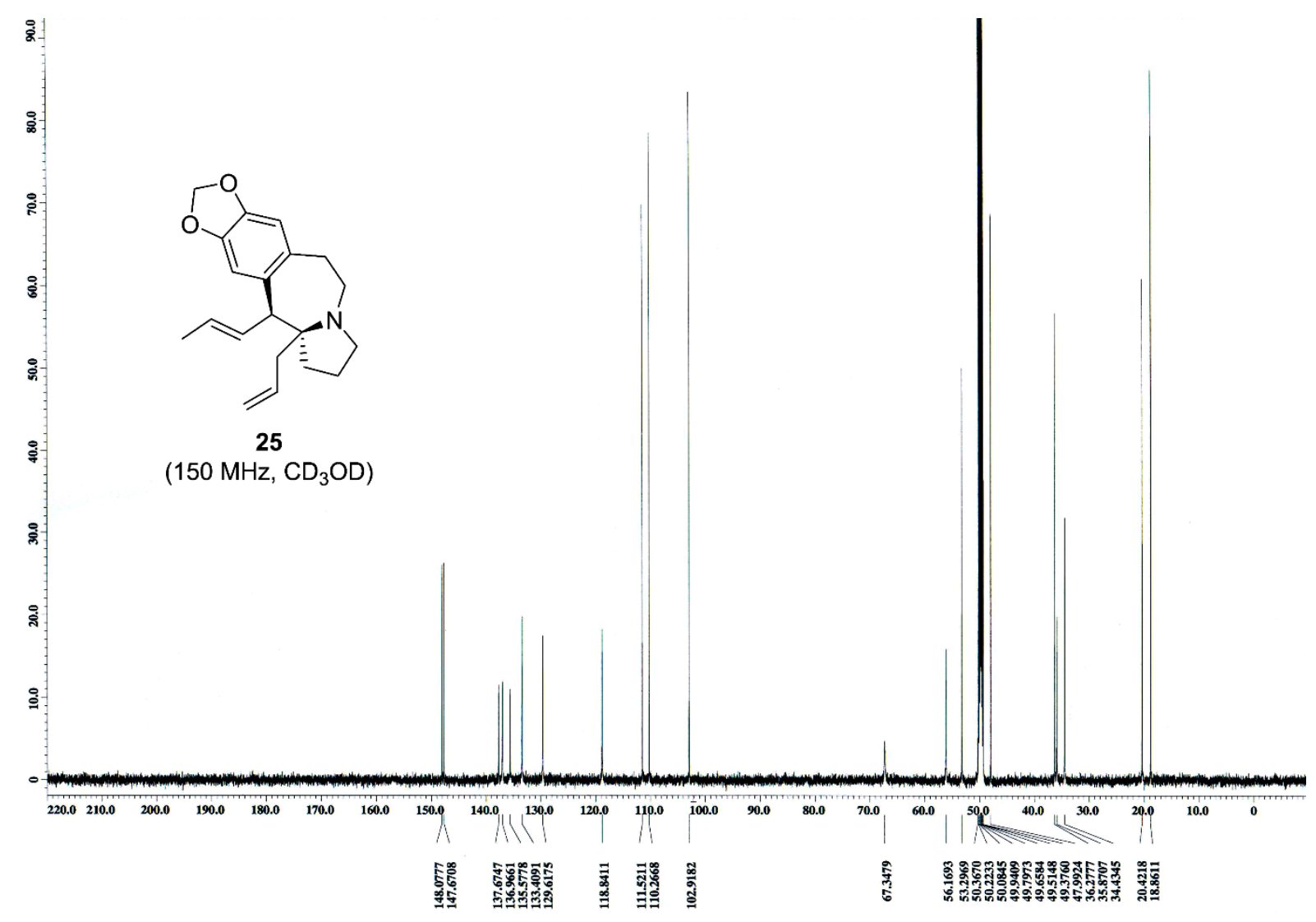

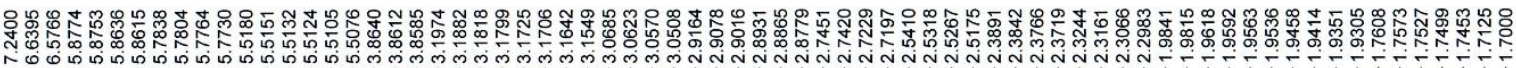

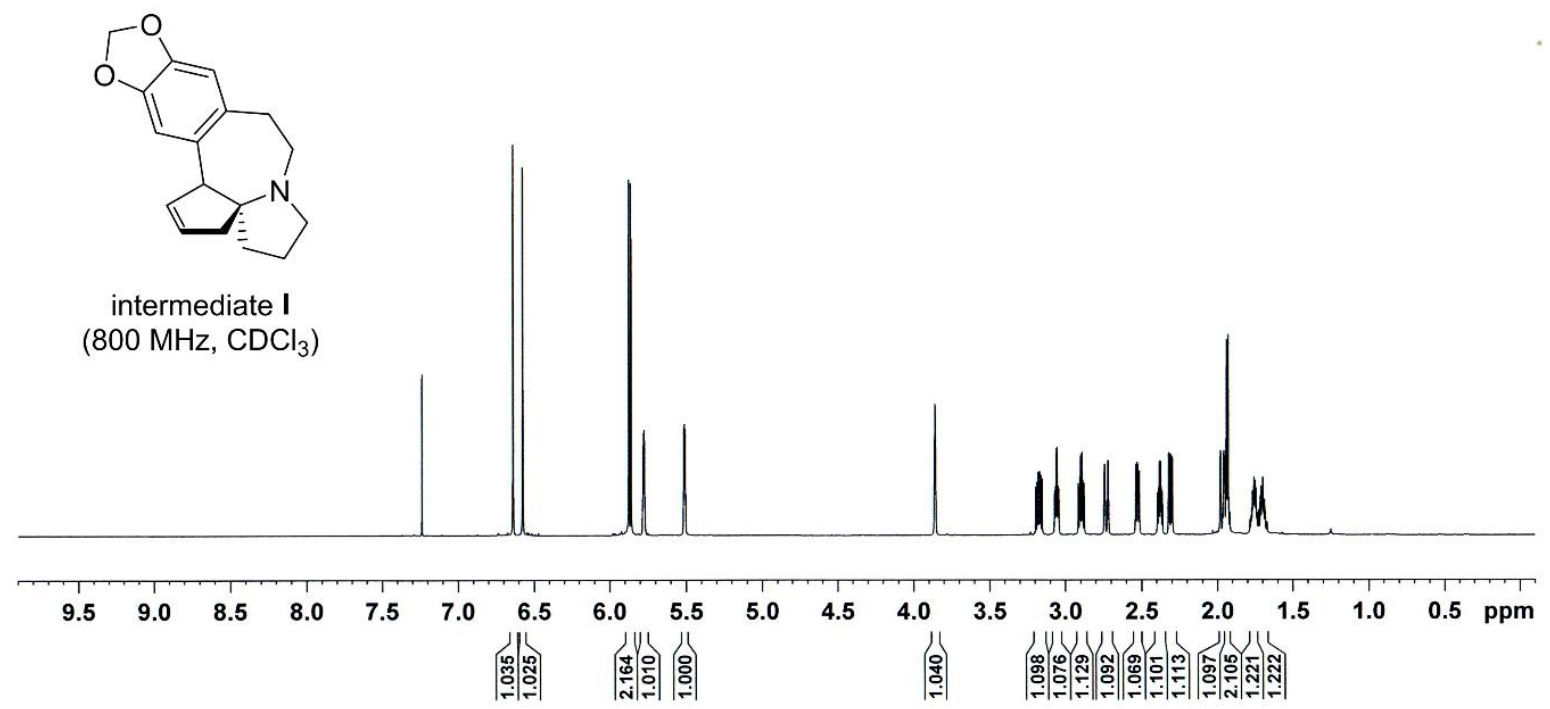




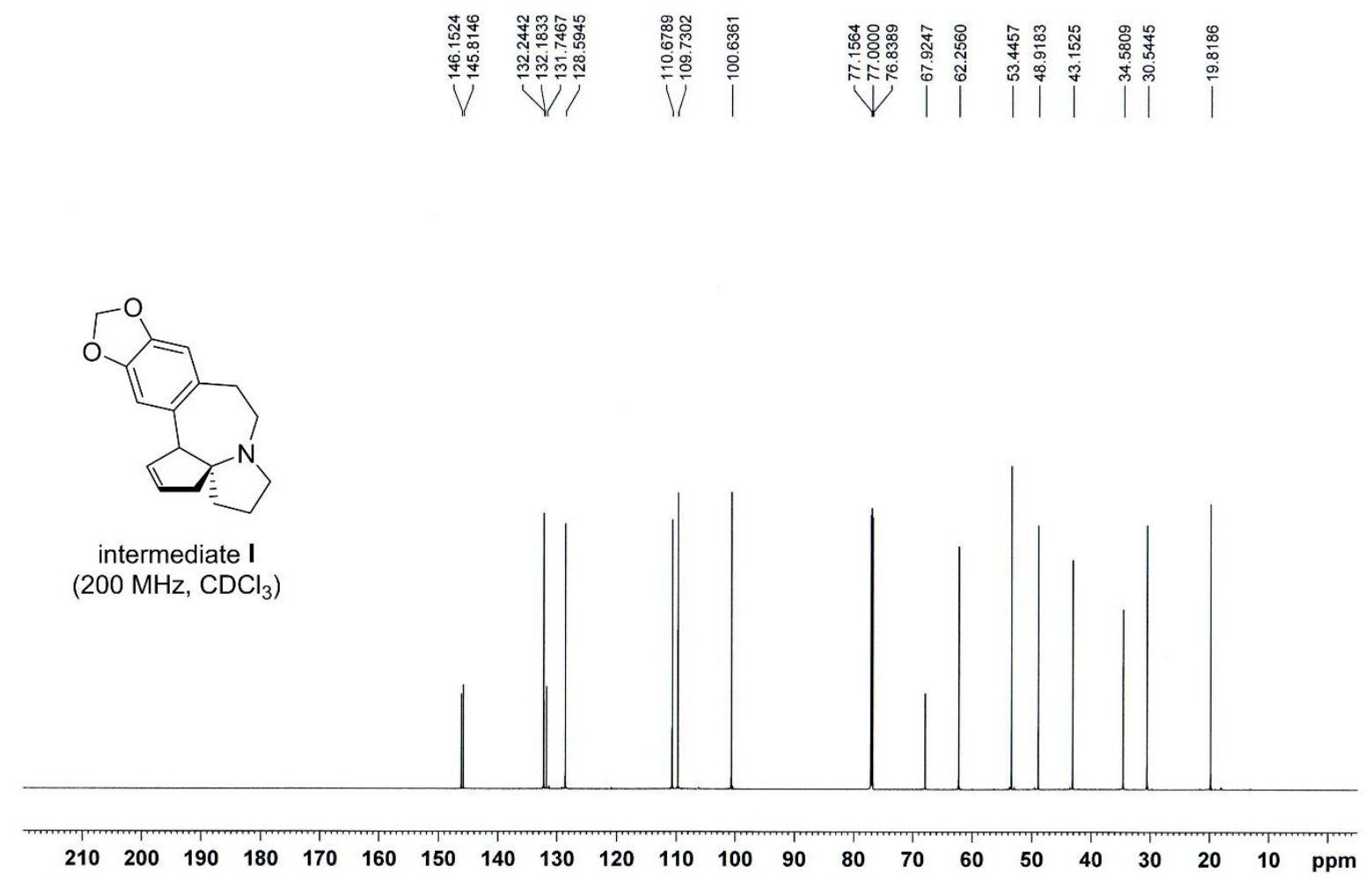

